\title{
Competition between the Brain and Testes under Selenium- Compromised Conditions: Insight into Sex Differences in Selenium Metabolism and Risk of Neurodevelopmental
} Disease

\author{
Matthew W. Pitts, ${ }^{1 \star}$ Penny M. Kremer, ${ }^{1 \star}$ Ann C. Hashimoto,,${ }^{1}$ Daniel J. Torres, ${ }^{1}$ China N. Byrns, ${ }^{1}$ \\ Christopher S. Williams, ${ }^{2}$ and Marla J. Berry ${ }^{1}$ \\ ${ }^{1}$ Department of Cell and Molecular Biology, John A. Burns School of Medicine, University of Hawaii, Honolulu, Hawaii 96813, and ${ }^{2}$ Department of Medicine \\ and Cancer Biology, Vanderbilt University School of Medicine, Nashville, Tennessee 37232
}

Selenium (Se) is essential for both brain development and male fertility. Male mice lacking two key genes involved in Se metabolism $\left(S c l{ }^{-1-} S_{P p p 1^{-1-}}\right.$ mice), selenoprotein P (Sepp1) and Sec lyase (Scly), develop severe neurological dysfunction, neurodegeneration, and

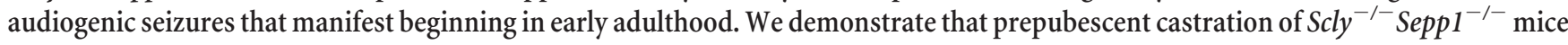
prevents behavioral deficits, attenuates neurodegeneration, rescues maturation of GABAergic inhibition, and increases brain selenoprotein levels. Moreover, castration also yields similar neuroprotective benefits to $S e p p 1^{-/-}$and wild-type mice challenged with Se-deficient diets. Our data show that, under Se-compromised conditions, the brain and testes compete for Se utilization, with concomitant effects on neurodevelopment and neurodegeneration.

Key words: neurodegeneration; neurodevelopment; oxidative stress; parvalbumin interneurons; selenium; sex differences

\section{Significance Statement}

Selenium is an essential trace element that promotes male fertility and brain function. Herein, we report that prepubescent castration provides neuroprotection by increasing selenium-dependent antioxidant activity in the brain, revealing a competition between the brain and testes for selenium utilization. These findings provide novel insight into the interaction of sex and oxidative stress upon the developing brain and have potentially significant implications for the prevention of neurodevelopmental disorders characterized by aberrant excitatory/inhibitory balance, such as schizophrenia and epilepsy.

\section{Introduction}

Oxidative stress and sex are both implicated as significant risk factors in the etiology of several neurodevelopmental disorders. Selenium $(\mathrm{Se})$ is an essential trace element with antioxidant properties that is indispensable for normal brain development and

\footnotetext{
Received July 17, 2015; revised Sept. 4, 2015; accepted Sept. 28, 2015.

Author contributions: M.W.P., P.M.K., C.N.B., and M.J.B. designed research; M.W.P., P.M.K., A.C.H., D.J.T., and C.S.W. performed research; C.S.W. contributed unpublished reagents/analytic tools; M.W.P., P.M.K., and D.J.T. analyzed data; M.W.P. wrote the paper.

This work was supported by National Institutes of Health Grants G12 MD007601 and R01 DK47320 to M.J.B. We thank Rachel Rueli and Keelan Elliott for excellent technical assistance; and Shoshana Bar-Nun, Roger Davis, Matthias Hentze, P. Reed Larsen, Robert Nichols, Joel Richter, and Lucia Seale for valuable commentary during manuscript preparation.

The authors declare no competing financial interests.

${ }^{*}$ M.W.P. and P.M.K. contributed equally to this work as co-first authors.

Correspondence should be addressed to Dr. Matthew W. Pitts, Department of Cell and Molecular Biology, John A. Burns School of Medicine, University of Hawaii, 651 Ilalo Street, Honolulu, HI 96813. E-mail: mwpitts@hawaii.edu. DOI:10.1523/JNEUROSCI.2724-15.2015

Copyright $\odot 2015$ the authors $\quad 0270-6474 / 15 / 3515326-13 \$ 15.00 / 0$
}

male fertility. Under conditions of Se deficiency, Se levels plummet in most organs but are preferentially retained in the brain and testes. Moreover, Se supplementation has been widely reported to exert sexually dimorphic effects (for review, see Schomburg and Schweizer, 2009), and the highest rates of Se uptake have been found in the male reproductive system (Brown and Burk, 1973). This indicates that there are important sex-specific differences in Se metabolism.

The biochemical effects of Se are mediated by selenoproteins, a distinct class of proteins characterized by the cotranslational incorporation of Se in the form of the 21st amino acid, selenocysteine (Sec), at UGA codons, which otherwise serve as stop codons. Among selenoproteins, selenoprotein P (Sepp1) is unique in that it contains multiple Sec residues and acts in Se transport throughout the body. Se delivery to the brain and testes is accomplished primarily by Sepp1 binding to the lipoprotein receptor, ApoER2 (Burk et al., 2007; Olson et al., 2007). In mice, 
deletion of Sepp1 or ApoER2 results in male infertility and diminished Se levels in brain and testes (Andersen et al., 2003; Hill et al., 2003; Burk et al., 2007; Olson et al., 2007). Furthermore, administration of a Se-deficient diet to Sepp $1^{-1-}$ or ApoER2 $2^{-/-}$mice results in severe neurological dysfunction, exemplified by seizures and neurodegeneration in brain regions related to auditory and motor function (Valentine et al., 2008).

Following ApoER2-mediated endocytosis of Sepp1, Sec residues must be decomposed to allow Se to be reutilized for selenoprotein synthesis. This task is fulfilled by selenocysteine lyase (Scly), an enzyme that catalyzes the breakdown of Sec into L-alanine and selenide (Esaki et al., 1982). Our prior studies showed that Scly knock-out $\left(\mathrm{Scly}^{-1-}\right)$ mice display cognitive deficits, exhibit diminished brain GPx activity, and develop metabolic syndrome when challenged with a low Se diet (Raman et al., 2012; Seale et al., 2012). More recently, we demonstrated that Se-supplemented male mice lacking both Scly and Sepp1 $\left(\mathrm{Scly}^{-1-} \mathrm{Sepp}^{-{ }^{--}}\right)$have reduced survival, audiogenic seizures, and brainstem neurodegeneration akin to Se-deficient $\operatorname{Sepp} 1^{-/-}$ and ApoER2 ${ }^{-/-}$mice (Byrns et al., 2014).

In this report, we detail a time-dependent loss of GABAergic inhibition in the inferior colliculus (IC) of male $S c l y^{-/-} S e p p 1^{-/-}$ mice and show that prepubescent castration prevents behavioral deficits, attenuates neurodegeneration, rescues maturation of GABAergic inhibition, and increases brain selenoprotein levels. Subsequent experiments reveal that castration yields neuroprotective benefits to both Sepp $1^{-/-}$and wild-type (WT) mice challenged with Se-deficient diets. These studies provide evidence for a competition between the brain and testes for Se utilization under Se-compromised conditions, with concomitant effects on neurodevelopment and neurodegeneration.

\section{Materials and Methods}

Animals. Sepp $1^{-1-}$ and $S c l{ }^{-1-}$ Sepp1 $1^{-1-}$ mice on a C57BL/6 background were generated as previously described (Byrns et al., 2014). As male Sepp $1^{-I-}$ mice have been demonstrated to be infertile (Hill et al., 2003), heterozygotes $\left(S_{e p p 1^{+/-}}, S_{c l y}{ }^{-/-} S e p p 1^{+/-}\right)$were crossed to generate Sepp $1^{-/-}$and $S c l y^{-1-} S e p p 1^{-1-}$ subjects. C57BL/6 WT mice were used as controls. All mice were group housed, with the exception of those used in the MK-801 study. These mice were group housed until 8-10 weeks of age and then single housed $5 \mathrm{~d}$ before the onset of experiments. Behavioral testing was conducted on adult mice between the ages of 9 and 15 weeks during the light cycle. Procedures and experimental protocols were approved by the University of Hawaii's Institutional Animal Care and Use Committee. All efforts were made to minimize animal discomfort and the number of animals used.

Diet. Mice were fed standard laboratory chow $(\sim 0.25 \mathrm{ppm} \mathrm{Se})$ and Se-supplemented water (10 $\mu \mathrm{m}$ sodium selenite) ad libitum unless otherwise noted. Select groups of animals were administered a Torula-yeastbased diet that contains $<0.01 \mathrm{ppm}$ selenium beginning at either weaning (WT MK-801 challenge experiment) or at 10 weeks of age $\left(\right.$ Sepp1 $1^{-/-}$challenge experiment). Animals receiving a Se-deficient diet were also administered standard tap water without Se added.

Surgery. Four-week-old male mice were anesthetized with isoflurane and the surgical area was shaved and prepared with providone and ethanol. An abdominal incision was made near the groin area, and the skin was retracted to expose to the tunica. The tunica was then pierced, and the testes were exposed one at a time. The testes were removed by snipping off each testicle along with epididymis. Skin incisions were closed with 6.0 surgical silk. Sham animals were also anesthetized, shaved, and prepared with providone and ethanol. Postoperative care for all mice included analgesic administration.

MK-801 drug treatment. At 6 weeks of age, select mice received intraperitoneal injections of PBS or MK-801 (Sigma-Aldrich; $0.2 \mathrm{mg} / \mathrm{kg}$ in PBS) for 5 consecutive days. The chosen dosage was based upon prior studies that reported MK-801-induced neurotoxicity in the adult retro- splenial cortex $\left(\mathrm{ED}_{50}=0.32 \mathrm{mg} / \mathrm{kg}\right)$ (Olney et al., 1989) and that periadolescent MK-801 administration impairs the maturation of cortical GABAergic circuitry ( $0.1 \mathrm{mg} / \mathrm{kg}$ for 5 consecutive days) (Thomases et al., 2013).

Histology and immunohistochemistry. Mice were deeply anesthetized ( $1.2 \%$ avertin; $0.7 \mathrm{ml} / \mathrm{mouse}$ ) and perfused intracardially with cold $0.1 \mathrm{M} \mathrm{PB}$ followed by $4 \%$ PFA in PB. Brains were removed, stored in $4 \%$ PFA for $24 \mathrm{~h}$, immersed in graded solutions of sucrose $(10 \%, 20 \%, 30 \%)$, and then cut into $40 \mu \mathrm{m}$ coronal sections. For DAB immunohistochemistry, sections were treated with $0.3 \% \mathrm{H}_{2} \mathrm{O}_{2}$ to inactivate endogenous peroxidases, blocked, and incubated overnight at $4^{\circ} \mathrm{C}$ with the proper primary antibody. The next day, sections were probed with the appropriate biotinylated secondary antibody followed by incubation in avidin-biotin-peroxidase complex (ABC Elite Kit, Vector Labs), and immunoreactivity was visualized by peroxidase detection using diaminobenzidine tetrahydrochloride (DAB; DAB Substrate Kit, Vector Labs) as a chromogen substrate. After several rinses in PBS, sections were mounted on slides, dehydrated with graded solutions of EtOH followed by xylene, and coverslipped. For immunofluorescence, a similar procedure was used, except that appropriate AlexaFluor-labeled fluorescent secondary antibodies were used for visualization instead of DAB. To label perineuronal nets (PNNs), sections were incubated in a solution containing biotinylated Wisteria floribunda lectin (1:1000; Sigma, L1516), washed, and then incubated with fluorescent avidin (1:500; Vector Labs) for visualization.

Silver staining. Silver staining was performed using the FD Neurosilver Kit II (FD Neurotechnologies) according to the manufacturer's instructions.

Protein extraction and immunoblotting. Mice were asphyxiated with $\mathrm{CO}_{2}$, and brains were quickly removed. Brains were cut in half along the longitudinal fissure, with one hemisphere being snap-frozen in liquid nitrogen for later use as a whole-brain sample. For the remaining hemisphere, the cerebellum, brainstem, cortex, and hippocampus were dissected out and snap-frozen in liquid nitrogen for later analysis. Frozen tissues were lysed by sonication in CelLytic MT buffer (Sigma-Aldrich) containing protease inhibitors (Calbiochem) and centrifuged at $14,000 \times g$ for $10 \mathrm{~min}$ at $4^{\circ} \mathrm{C}$. Supernatants were collected, and the protein concentrations were measured using Bradford assay. For Western blotting, $40 \mu \mathrm{g}$ samples of total protein were separated on $4 \%-20 \%$ SDS-PAGE gradient gels (Bio-Rad), transferred to Immobilon-FL PVDF membranes (Millipore), and probed for $2 \mathrm{~h}$ at room temperature with specific antibodies. Membranes were then incubated in the dark with secondary antibodies coupled to infrared fluorophores (LI-COR Biosciences). Blots were imaged and analyzed using an Odyssey infrared imager (LI-COR Biosciences). Relative protein levels were determined by dividing the optical density of the band representing the protein of interest by that of $\alpha$-tubulin (loading control). To simplify for comparative purposes, the mean normalized optical density for each protein of interest in sham Scly ${ }^{-1-}$ Sepp1 $1^{-1-}$ mice was recalibrated to equal 100.

Antibodies. The primary antibodies used for immunohistochemistry were as follows: mouse anti-GAD67 (1:20,000; EMD Millipore, MAB5406), rabbit anti-PGC-1 (1:200; Santa Cruz Biotechnology, sc13067), rabbit anti-GFAP (1:2000; DAKO, Z0334), goat anti-ApoER2 (1:50; Santa Cruz Biotechnology, sc-10113), rabbit anti-selenophosphate synthetase 2 (1:1000; Rockland, 200-401-999), rabbit anti-parvalbumin (1:5000; Swant, PV 25), and rabbit anti-c-Fos (1:5000; EMD Millipore, PC38). The primary antibodies used for Western blotting were as follows: mouse anti- $\alpha$-tubulin (1:5000; Novus Biologicals, NB100-690), rabbit anti-PGC-1 (1:1000; EMD Millipore, AB3242), goat anti-glutathione peroxidase 1 (1:500; R\&D Systems, AF3798), rabbit anti-GPx4 (1:1000; Cayman Chemical, 10005258), and rabbit anti-SelM (1:500; SigmaAldrich, HPA019601).

Rotorod. Motor coordination was tested using a standard rotorod apparatus (Stoelting). Mice were placed on a horizontal rod that began rotating at $4 \mathrm{rpm}$ and increased to $40 \mathrm{rpm}$ over a $5 \mathrm{~min}$ period. Mice were tested four times daily for two consecutive days with an intertrial interval of $30 \mathrm{~min}$. The latency to fall off the rod was recorded and used to calculate an average for all eight trials.

Open field test. Mice were placed in the center of an open field apparatus $(50 \times 50 \mathrm{~cm})$ with $40 \mathrm{~cm}$ high opaque walls and allowed to explore for $5 \mathrm{~min}$. Animal movement was recorded by an overhead video camera 
connected to a PC and analyzed by video tracking software (VideoMot 2, TSE Systems).

Assessment of audiogenic seizures. Mice were placed in the open field apparatus for a 5 min test, during which the initial $150 \mathrm{~s}$ served as a silent habituation period, followed by $85 \mathrm{~dB}$ white noise played through a loudspeaker for the remainder of the trial. At 90 min after testing, mice were deeply anesthetized, perfused, and brains were processed for histological analysis.

Barnes maze test. Spatial learning and memory were assessed using the Barnes maze (TSE Systems) as described previously (Pitts et al., 2013). In brief, the maze consists of a white circular board containing 40 equally spaced holes, with one hole leading to an escape tunnel. Mice were trained to find the escape tunnel, which remained at a fixed location relative to spatial cues for the duration of training. Training consisted of 2 trials daily ( 3 min max per trial) for $10 \mathrm{~d}$, with the starting location varying pseudorandomly. The trial ended when the mouse entered the escape tunnel or $3 \mathrm{~min}$ elapsed. If a mouse failed to find the escape tunnel within the $3 \mathrm{~min}$ trial period, it was placed in the escape tunnel by the researcher and allowed to stay there for $15 \mathrm{~s}$. For each training trial, the latency to locate the escape tunnel and the number of incorrect holes checked (errors) before locating the escape tunnel were recorded.

Se analysis. Se was measured using a modification of the fluorometric assay of Koh and Benson (1983) and Sheehan and Gao (1990). Tissue was predigested in $6 \mathrm{ml}$ of nitric acid at $150^{\circ} \mathrm{C}$ followed by digestion with 500 $\mu \mathrm{l}$ perchloric:nitric acid (1:4) solution at $190^{\circ}$ over $1.5 \mathrm{~h}$. As solution cooled to $150^{\circ} \mathrm{C}, 0.5 \mathrm{ml}$ of concentrated $\mathrm{HCl}$ was added, and samples were maintained between $125^{\circ} \mathrm{C}$ and $150^{\circ} \mathrm{C}$ for $30 \mathrm{~min}$. Next, $2 \mathrm{ml}$ of 0.1 $\mathrm{M}$ EDTA and $0.5 \mathrm{ml}$ of 2,3 diaminonaphthalene were added, followed by $3 \mathrm{ml}$ of cyclohexane and incubation at $60^{\circ} \mathrm{C}$ for $30 \mathrm{~min}$. Fluorescence was measured in a PerkinElmer LS 55 fluorometer and concentrations determined via comparison with a standard curve.

Glutathione peroxidase activity assay. Soluble proteins were extracted as described above. Glutathione peroxidase activity was measured as the reduction rate of tert-butylhydroperoxide catalyzed by the samples upon the oxidation of glutathione and reduced NADPH. A unit of activity was defined as the consumption of $1 \mu \mathrm{mol}$ of NADPH per minute, calculated from the expression $\left(V_{\max } \times V_{t} / V_{s}\right) /(0.0062 \times \mathrm{D})$, using $0.0062 \mu \mathrm{M}^{-1}$ $\mathrm{cm}^{-1}$ as the extinction coefficient for NADPH at $340 \mathrm{~nm}$.

Testosterone measurement. Blood was collected from adult mice $($ age $=$ $8-10$ weeks) into serum separator tubes via cardiac puncture during the early evening period (4:00-6:00 P.M.). Serum testosterone levels were then determined by means of a testosterone ELISA kit (Crystal Chem).

Stereology. Analysis of cell density was performed on a Zeiss microscope (Axioskop2) equipped with Stereo Investigator software (MBF Bioscience). An optical dissector (counting box) was used to count cells. With the aid of a mouse brain atlas (Paxinos and Franklin, 2004), the retrosplenial granular cortex and IC were outlined using a $5 \times$ objective at specified levels relative to bregma (retrosplenial granular cortex $=$ $-1.46 \mathrm{~mm}, \mathrm{IC}=-5.02 \mathrm{~mm}$ ). Following contour selection, optical fractionator analysis was conducted at high magnification ( $20 \times$ objective) using a $300 \times 300 \mu \mathrm{m}$ counting frame to quantify the number of positively labeled cells. At each counting site, the mounted section thickness was determined. Mean section thickness was calculated by averaging all counting sites, and this value was used to determine the number of positively labeled cells per unit volume. For double-label experiments, parvalbumin (PV)-positive cells (red) were counted first. Next, the emission filter was switched, and WFA-positive cells (green) were counted by revisiting the same sites previously sampled. Finally, counting sites were revisited again and cells with overlapping markers (PV, WFA) were counted as PNN-labeled PV interneurons.

Quantification of immunohistochemistry and silver staining. The optical density of Gad67 and GFAP immunoreactivity (IR) in the IC was quantified at the same coronal level $(-5.02)$ as used for stereology. Brightfield images $(5 \times$ objective $)$ were captured with a digital camera mounted on a Zeiss microscope (Axioskop2), imported into ImageJ analysis software, and converted to black-and-white images. To quantify Gad67 IR, contours were drawn around the IC and the adjacent lateral periaqueductal gray (LPAG) with the aid of a mouse brain atlas (Paxinos and Franklin, 2004). The contour around the IC was selected for positive IR, whereas the adjacent LPAG was used as a background control. Mean optical density was determined as the difference between the IC and LPAG density. For measuring GFAP levels, a similar procedure was used, except that the LPAG was not used as a background control because GFAP IR was abundant under baseline conditions. Quantification of silver staining for the decussation of the superior cerebellar peduncle (XSCP) $(-4.48 \mathrm{~mm})$ and the IC $(-5.02 \mathrm{~mm})$ was determined using similar methodology.

Statistical analysis. Data were analyzed and plotted using Prism version 4.0c (GraphPad Software). Immunohistochemistry data for each time point (4 weeks, 8 weeks) were compared using one-way ANOVAs followed post hoc by Tukey's multiple-comparison test. Pairwise comparisons between sham and castrated animals were conducted using Student's $t$ tests. Two-way repeated measure ANOVAs were used to evaluate behavioral data compiled over multiple time points (audiogenic seizure test, rotorod time course, Barnes maze) followed by Bonferroni post-tests. For the MK-801 study, one-way ANOVAs were used to compare data between treatment groups followed by post hoc Tukey's tests. All results are represented as mean \pm SEM.

\section{Results}

Impaired development of normal GABAergic inhibition in the IC of male $S c l y^{-/-} S e p p 1^{-/-}$mice

Male $S c l y^{-1-} \operatorname{Sepp} 1^{-/-}$mice were previously shown to display audiogenic seizures in response to mild white noise (85 dB) (Byrns et al., 2014). This coincided with diminished Gad67 expression, a reduced density of PV interneurons, and neurodegeneration in the $\mathrm{IC}$, a region implicated in audiogenic seizures (for review, see Faingold, 2002). In this study, we first examined the developmental time course of markers related to GABAergic inhibition and oxidative stress in the IC of male $\mathrm{Scly}^{-1-} \mathrm{Sepp} \mathrm{1}^{-1-}$ mice relative to WT and Sepp1 $1^{-/-}$controls. Time points were investigated at 4 weeks of age, when male $S c l y^{-1-} S e p p 1^{-1-}$ mice exhibit no obvious symptoms, and at 8 weeks of age, when neurological dysfunction is apparent. No differences in IC Gad67 expression were observed at 4 weeks, whereas by 8 weeks, levels differed among genotypes $\left(F_{(2,7)}=5.766, p<0.05\right)$, as levels were significantly reduced in $S c l y^{-/-} S e p p 1^{-1-}$ mice relative to WT controls $(p<0.05)$ (Fig. 1A,B). We also examined expression of the transcriptional coactivator PPAR $\gamma$ (PGC-1), a master regulator of ROS metabolism that protects against neurodegeneration by inducing expression of antioxidant genes (St-Pierre et al., 2006). PGC-1 is primarily expressed in GABAergic interneurons (Cowell et al., 2007) and is essential for normal function of PV interneurons (Lucas et al., 2014). At 4 weeks, PGC-1 expression was comparable between groups, but by 8 weeks, the density of IC PGC-1 positive cells was significantly reduced in Scly ${ }^{-1-}$ Sepp1 $1^{-1-}$ mice compared with WT controls $\left(F_{(2,6)}=\right.$ 5.801, $p<0.05$; Scly ${ }^{-/}$Sepp1 $1^{-/-}$vs WT, $p<0.05$ ) (Fig. $1 C, D$ ). Immunohistochemistry for GFAP, a marker of reactive gliosis, indicated that IC GFAP levels were significantly elevated in $S c l y^{-/-}$Sepp $1^{-/-}$mice at 4 weeks $\left(F_{(2,9)}=8.238, p<0.01\right.$; Scly ${ }^{-/-}$Sepp1 $1^{-1-}$ vs WT and Scly ${ }^{-1-}$ Sepp1 $1^{-1-}$ vs Sepp1 ${ }^{-1-}, p<$ $0.05)$ and remained increased relative to the other groups at 8 weeks $\left(F_{(2,8)}=20.70, p<0.001 ;\right.$ Scly $^{-/-}$Sepp1 $1^{-1-}$ vs WT and $S c l y^{-/-} \operatorname{Sepp1} 1^{-/-}$vs Sepp1 $1^{-1-}, p<0.01$ ) (Fig. 1E,F). These results demonstrate that redox imbalance precedes the developmental loss of Gad67 and PGC-1 expression in Scly ${ }^{-/-}$Sepp $1^{-1-}$ mice. We also observed that, in multiple brain regions, including the IC and retrosplenial cortex, PGC-1 expression occurs largely in PV interneurons expressing the Sepp1 receptor, ApoER2 (Fig. $2 A)$. Moreover, expression of selenophosphate synthetase 2 (SPS2), the enzyme that generates the monoselenophosphate required for selenoprotein synthesis, was also found predominantly in ApoER2-expressing PV interneurons (Fig. 2B). 
A

4 Weeks

8 Weeks

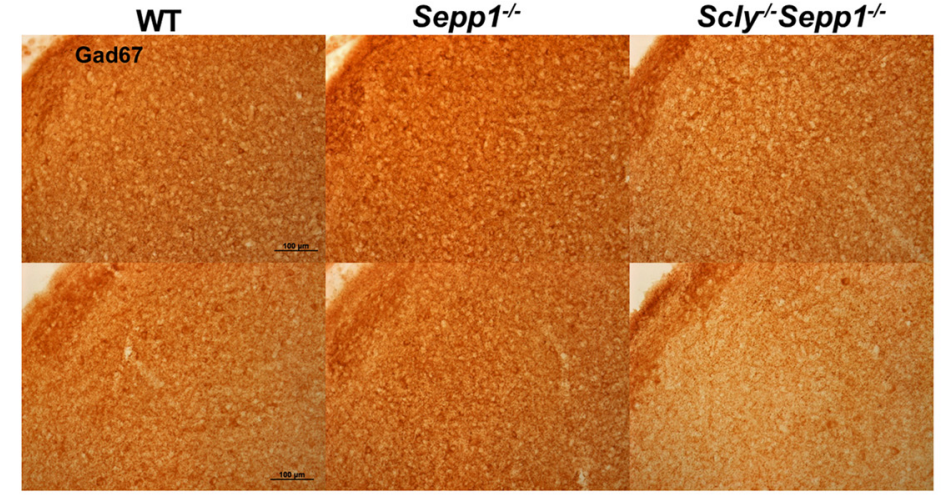

C

4 Weeks

8 Weeks

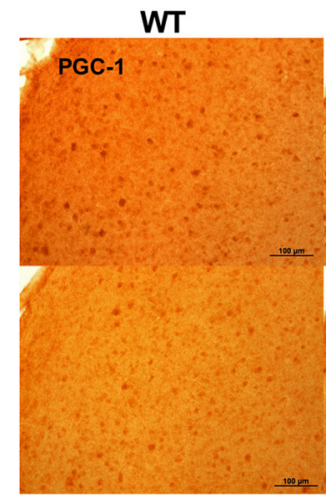

E

4 Weeks

8 Weeks

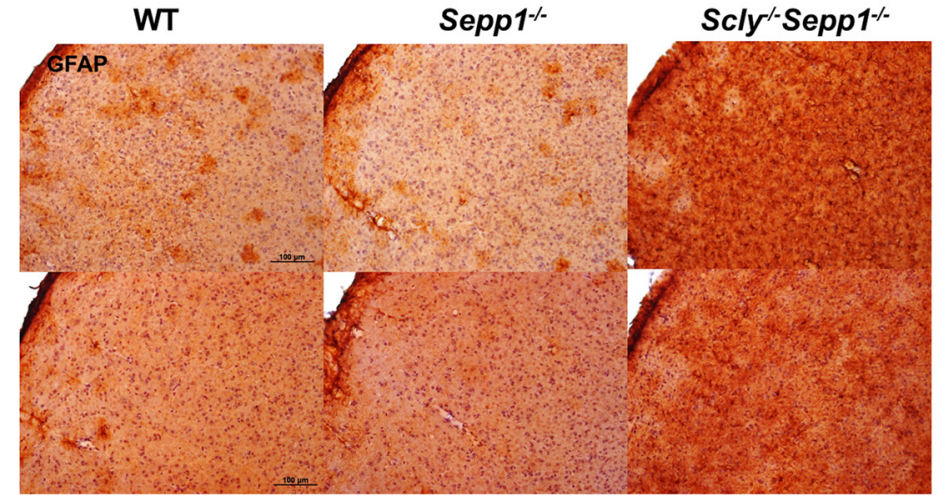

B

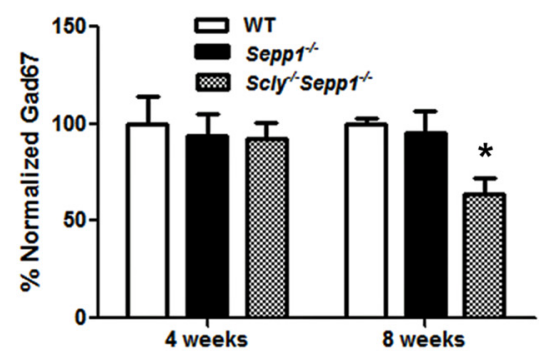

D

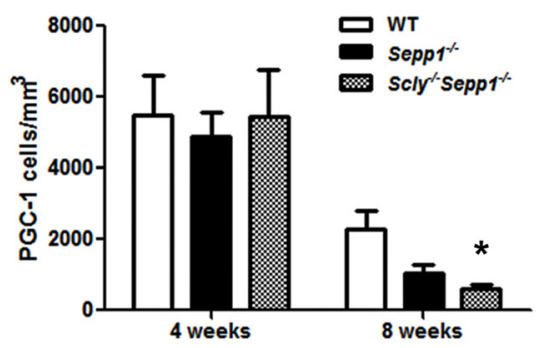

$\mathbf{F}$

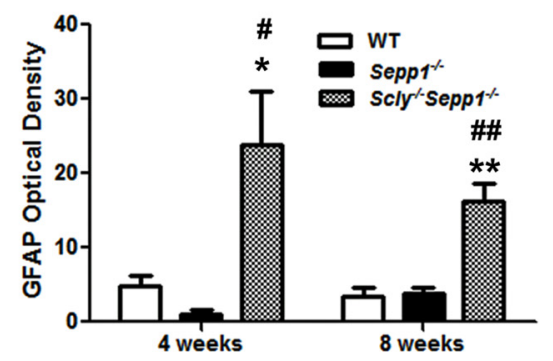

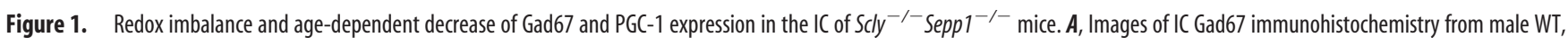
Sepp $1^{-1-}$, and SCly ${ }^{-1-}$ Sepp $1^{-1-}$ mice at 4 and 8 weeks of age. $B$, Mean ( \pm SEM) normalized Gad 67 optical density relative to WT controls. $C$, Images of IC PGC-1 immunohistochemistry from male WT, Sepp $1^{-/-}$, and Scly ${ }^{-/-}$Sepp $1^{-/-}$mice. D, Mean ( \pm SEM) density of PGC -1 cells per $\mathrm{mm}^{3}$. E, Images of IC GFAP immunohistochemistry from male WT, Sepp $1^{-/-}$, and Scly ${ }^{-/-}$Sepp $1^{-/-}$ mice. F, Mean ( \pm SEM) GFAP optical density $\left(n=3\right.$ or 4 per group per time point). ${ }^{*} p<0.05$ compared with WT. ${ }^{* *} p<0.01$ compared with WT. ${ }^{\#} p<0.05$ compared with Sepp $1^{-/-}$. \#\# $p<0.01$ compared with Sepp $1^{-1-}$. Scale bar, $100 \mu \mathrm{m}$.

We next investigated the maturation of PV interneurons in the IC using double-label immunohistochemistry for PV and perineuronal nets (PNNs). PNNs are heterogeneous aggregates of extracellular matrix molecules, which form lattice-like structures that preferentially encase the cell body of PV interneurons (Härtig et al., 1992). The development of these structures continues into adolescence, and PNN formation has been used as a marker of PV interneuron maturation in recent studies (Cabungcal et al., 2013, et al., 2014). Whereas mature PNNs are neuroprotective, redox imbalance during development prevents PNN formation around PV interneurons (Cabungcal et al., 2013). At 4 weeks, we observed no differences between genotypes for the density of PV interneurons or density of PNN-labeled PV interneurons within the IC (Fig. $3 A, C, D$ ). When examined at 8 weeks, we observed a significant main effect of genotype for PV interneuron density $\left(F_{(2,8)}=5.188, p<0.05\right)$ and post hoc pairwise comparisons approached significance $\left(S c l y^{-/-} \operatorname{Sep} p 1^{-/-}\right.$vs WT, $\left.p=0.07\right)$ (Fig. $3 B, C$ ). Moreover, we also found that the density of PNNlabeled PV interneurons significantly differed between genotypes $\left(F_{(2,8)}=11.73, p<0.01\right)$, as $S c l y^{-1-} \operatorname{Sepp} 1^{-/-}$mice displayed a reduced density compared with the other groups $\left(S c l y^{-/-} S e p p 1^{-1-}\right.$ vs WT and Scly ${ }^{-/-} S e p p 1^{-/-}$vs Sepp1 $1^{-/-}$, $p<0.05)($ Fig. $3 B, D)$.

Castration of juvenile $S c l y^{-/-} \operatorname{Sepp} 1^{-/-}$mice prevents behavioral deficits, promotes maturation of PV interneurons in the IC, and attenuates brainstem neurodegeneration Our prior studies determined that male $S c l y^{-/} \operatorname{Sepp1^{-/-}}$ mice develop neurological dysfunction beginning at $\sim 6$ weeks of age, 
A
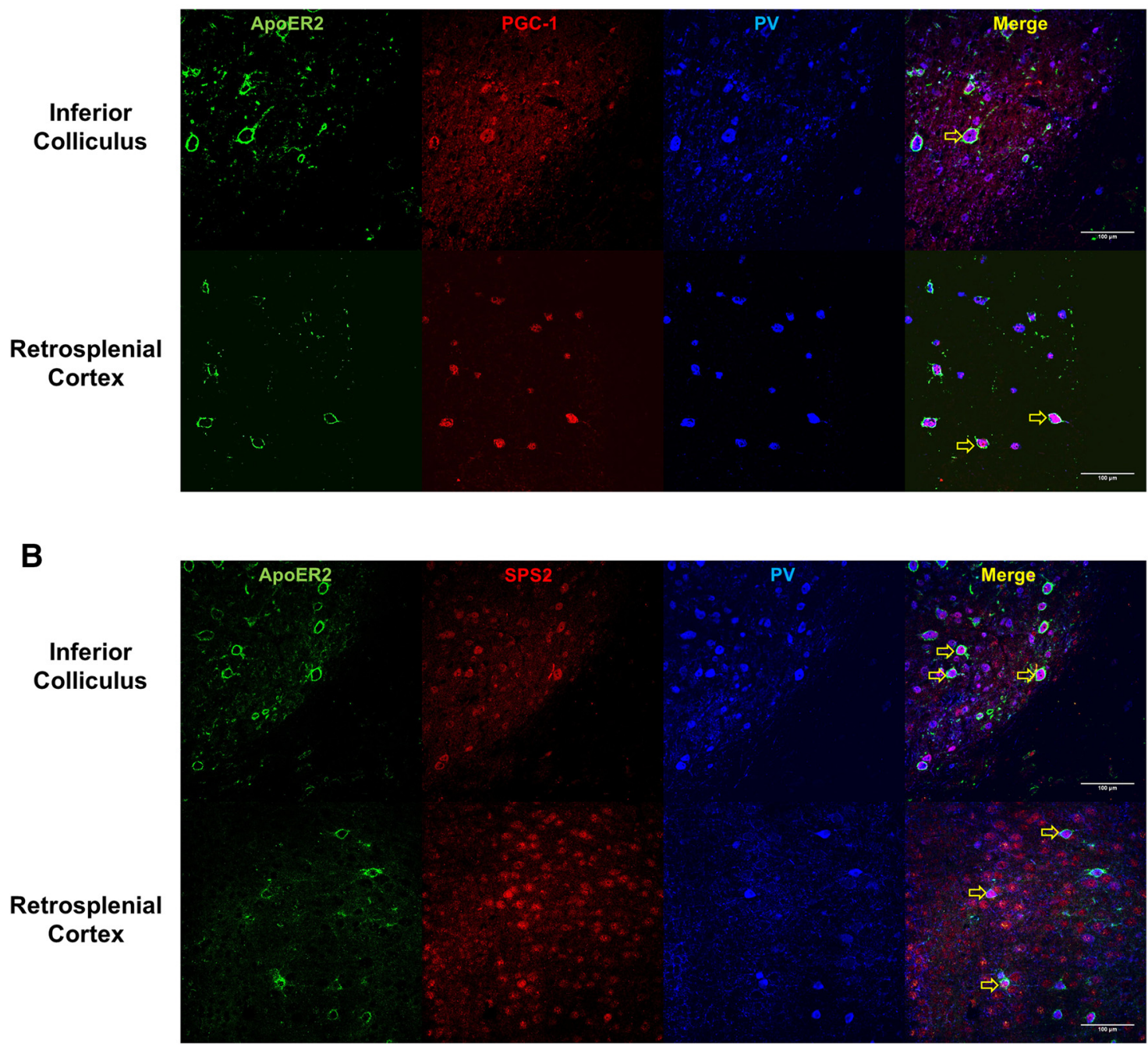

Figure 2. ApoER2 is preferentially expressed on metabolically active PV interneurons that comprise major sites of selenoprotein synthesis. A, Images of ApoER2 (green), PGC-1 (red), and PV (blue) in the IC and retrosplenial cortex. B, Images of ApoER2 (green), selenophosphate synthetase 2 (SPS2; red), and PV (blue) in the IC and retrosplenial cortex. Yellow arrows indicate triple-labeled neurons in merged images. Scale bar, $100 \mu \mathrm{m}$.

whereas female $S c l y^{-1-} \operatorname{Sepp} 1^{-\prime-}$ mice are relatively unaffected (Byrns et al., 2014). To investigate whether the presence of testes was adversely affecting male $S c l y^{-1-} S e p p 1^{-1-}$ mice, we castrated male $S c l y^{-1-} \operatorname{Sepp} 1^{-1-}$ mice at 4 weeks of age, before the onset of neurological deficits (Fig. 4A). Relative to sham $\mathrm{Scly}^{-1-} \mathrm{Sepp1}^{-1-}$ mice, castration increased survival (Fig. $4 B$ ) and significantly improved both motor performance on the rotorod $\left(t_{(22)}=3.422\right.$, $p<0.01)$ and locomotion in the open field test $\left(t_{(20)}=2.886, p<\right.$ 0.01 ) (Fig. $4 C, D$ ). Mice were also tested in a modified version of the open field test in which mild white noise $(85 \mathrm{~dB})$ was administered through an overhead loudspeaker during the second half of the test. Two-way ANOVA revealed significant main effects on locomotion for both sound $\left(F_{(1,19)}=25.51, p<0.001\right)$ and castration $\left(F_{(1,19)}=7.323, p<0.05\right)$, along with a significant interaction effect $\left(F_{(1,19)}=22.69, p<0.001\right)$ (Fig. $\left.4 E\right)$. Post hoc analysis determined that there were significant differences in locomotion between sham and castrated $S c l y^{-1-} \operatorname{Sepp}^{-1-}$ mice in response to noise $\left(t_{(19)}=5.329, p<0.01\right)$, as uncontrolled running behavior was elicited in multiple sham $S c l y^{-1-} S e p p 1^{-1-}$ mice. Moreover, castration resulted in significantly reduced $\mathrm{cFos}$ expression in the IC $\left(t_{(10)}=2.466, p<0.05\right)$, indicative of dimin- ished neural activation in response to noise (Fig. $4 F, G$ ). Neurodegeneration was also assessed by means of silver staining, to determine whether castration attenuates the brainstem neurodegeneration characteristically found in $\mathrm{Scly}^{-1} \mathrm{Sepp1^{-/- }}$ mice. Castrated mice exhibited significantly reduced levels of silver staining in both the XSCP $\left(t_{(4)}=4.906, p<0.01\right)$ and the IC $\left(t_{(4)}=5.55, p<0.01\right)$ (Fig. $\left.4 H, I\right)$. Within the IC, castrated mice exhibited significantly reduced GFAP levels $\left(t_{(10)}=2.236, p<\right.$ $0.05)$ and showed nonsignificant trends toward elevated Gad67 expression $(p=0.37)$ and an increased density of PGC-1positive cells $(p=0.42)$ (Fig. $5 A-D)$. Moreover, castration promoted the maturation of IC PV interneurons, as castrated mice had an increased density of PNN-labeled PV interneurons $\left(t_{(7)}=\right.$ 2.446, $p<0.05$ ) (Fig. $5 E-G$ ).

\section{Castration of juvenile $S c l y^{-/} S e p p 1^{-/-}$mice increases brain} selenoprotein levels in adulthood

We next evaluated whether castration resulted in elevated selenoprotein and Se levels in the brain. Western blot analyses determined that brainstem levels of GPx4 were significantly elevated in castrated animals $\left(t_{(6)}=2.478, p<0.05\right.$ ) (Fig. 
A

WT

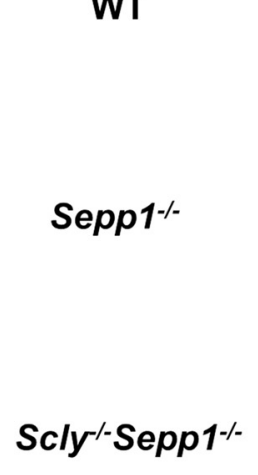

B

WT

Sepp1\%

Scly/-Sepp1/-
Age $=4$ Weeks

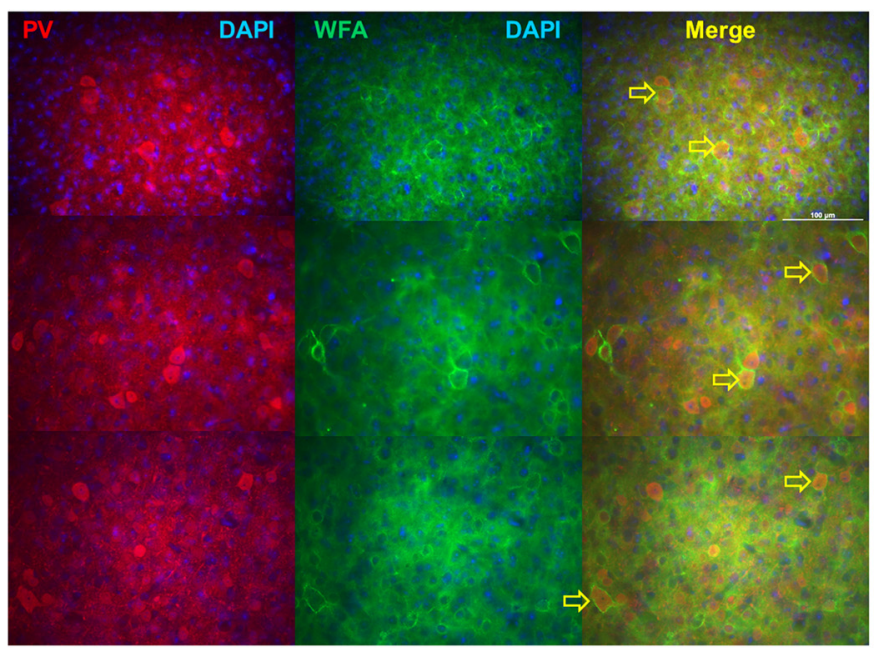

Age $=8$ Weeks

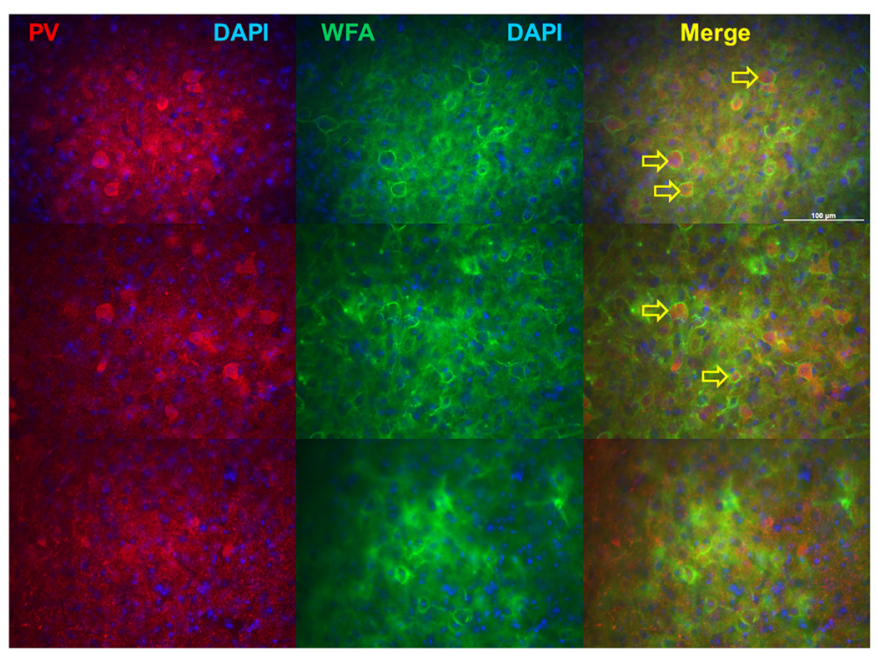

C

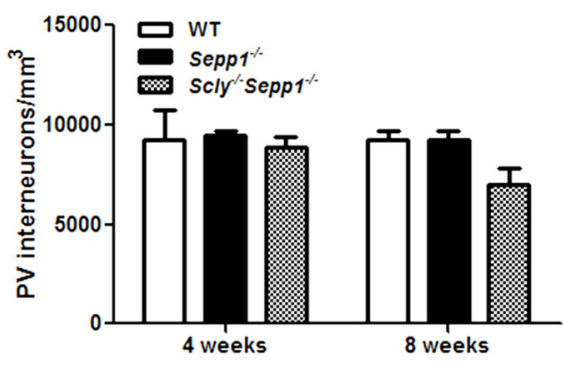

D

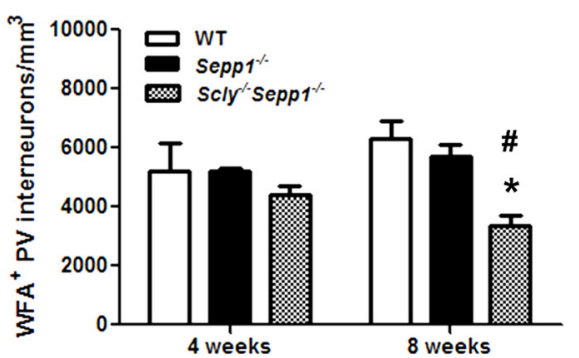

Figure 3. Impaired maturation of ICPV interneurons in Scly ${ }^{-/}$Sepp $1^{-/-}$mice. A, Immunofluorescentimages of PV (red) and WFA (green) from the IC of WT, Sepp $1^{-/-}$, and Scly ${ }^{-/-}$Sepp $1^{-/-}$mice at 4 weeks. Yellow arrows indicate WFA-labeled PV interneurons in merged images. $\boldsymbol{B}$, Images taken at 8 weeks. C, Mean ( \pm SEM) density of PV interneurons per mm ${ }^{3}$. D, Mean ( \pm SEM) density of WFA-labeled PV interneurons per $\mathrm{mm}^{3}$ ( $n=3$ per genotype for each time point). ${ }^{*} p<0.05$ compared with WT. ${ }^{\#} p<0.05$ compared with Sepp ${ }^{-/-}$. Scale bar, $100 \mu \mathrm{m}$.

$6 A-C)$. In accord with our Western blot data, GPx activity was significantly elevated in samples of whole brain $\left(t_{(7)}=3.037\right.$, $p<0.05)$ and brainstem $\left(t_{(14)}=2.235, p<0.05\right)$ from castrated mice (Fig. 6D). Se analysis performed on whole-brain samples from male, castrated male, and female $S c l y^{-/-}$Sepp $1^{-/-}$mice also showed that Se levels significantly differed between groups $\left(F_{(2,12)}=24.34, p<0.001\right)$ (Fig. $6 E$ ). Post hoc analysis revealed that brain Se levels were significantly elevated in castrated male $(p<0.05)$ and female mice $(p<$ $0.001)$ relative to male $S c l y^{-1-} \operatorname{Sepp1} 1^{-1-}$ counterparts. In addition, we compared Se levels between male WT, Sepp $1^{-/-}$, and $S c l y^{-/-}$Sepp $1^{-/-}$mice in brain and testes (Fig. $6 F, G$ ). For both brain $\left(F_{(2,13)}=38.21, p<0.0001\right)$ and testes $\left(F_{(2,13)}=\right.$ 236.1, $p<0.0001)$, Se content differed between genotypes, with levels significantly reduced in Sepp1 $1^{-/-}$(brain: $p<0.01$; testes: $p<0.001$ ) and $S c l y^{-1-} \operatorname{Sepp1} 1^{-1-}$ mice (brain: $p<0.001$; testes: $p<0.001)$ relative to WT controls. In addition, male Scly ${ }^{-/-}$Sepp1 $1^{-1-}$ mice exhibited a trend toward reduced testosterone levels relative to the other genotypes that did not reach statistical significance $(p=0.3965)$ (Fig. $6 H)$.
Castration of juvenile Sepp $1^{-/-}$mice delays neurological dysfunction upon challenge with a Se-deficient diet

Our next study investigated whether castration would also provide neuroprotection to Sepp $1^{-/-}$mice. Prior reports show that, upon administration of a Se-deficient diet, Sepp $1^{-/-}$mice develop neurological dysfunction within a matter of weeks (Valentine et al., 2008). For our study, mice were fed standard laboratory chow and Se-supplemented water until 10 weeks of age, whereupon they were challenged by switching their diet to Se-deficient chow and unsupplemented water (Fig. 7A). Motor coordination was assessed on the rotorod immediately before administration of the Se-deficient diet and at 2 week intervals following the dietary change. Two-way ANOVA revealed a significant main effect of time $\left(F_{(2,36)}=6.661, p<0.01\right)$ and a significant time $\times$ castration interaction effect $\left(F_{(2,36)}=3.788\right.$, $p<0.05$ ) on rotorod performance. Scores were comparable between sham and castrated animals for the first two tests; but after 4 weeks on the Se-deficient diet, rotorod performance was significantly worse in sham Sepp1 $1^{-/-}$mice $\left(t_{(18)}=2.954, p<0.05\right)$ (Fig. $7 B$ ). After 5 weeks on the Se-deficient diet, sham mice began 

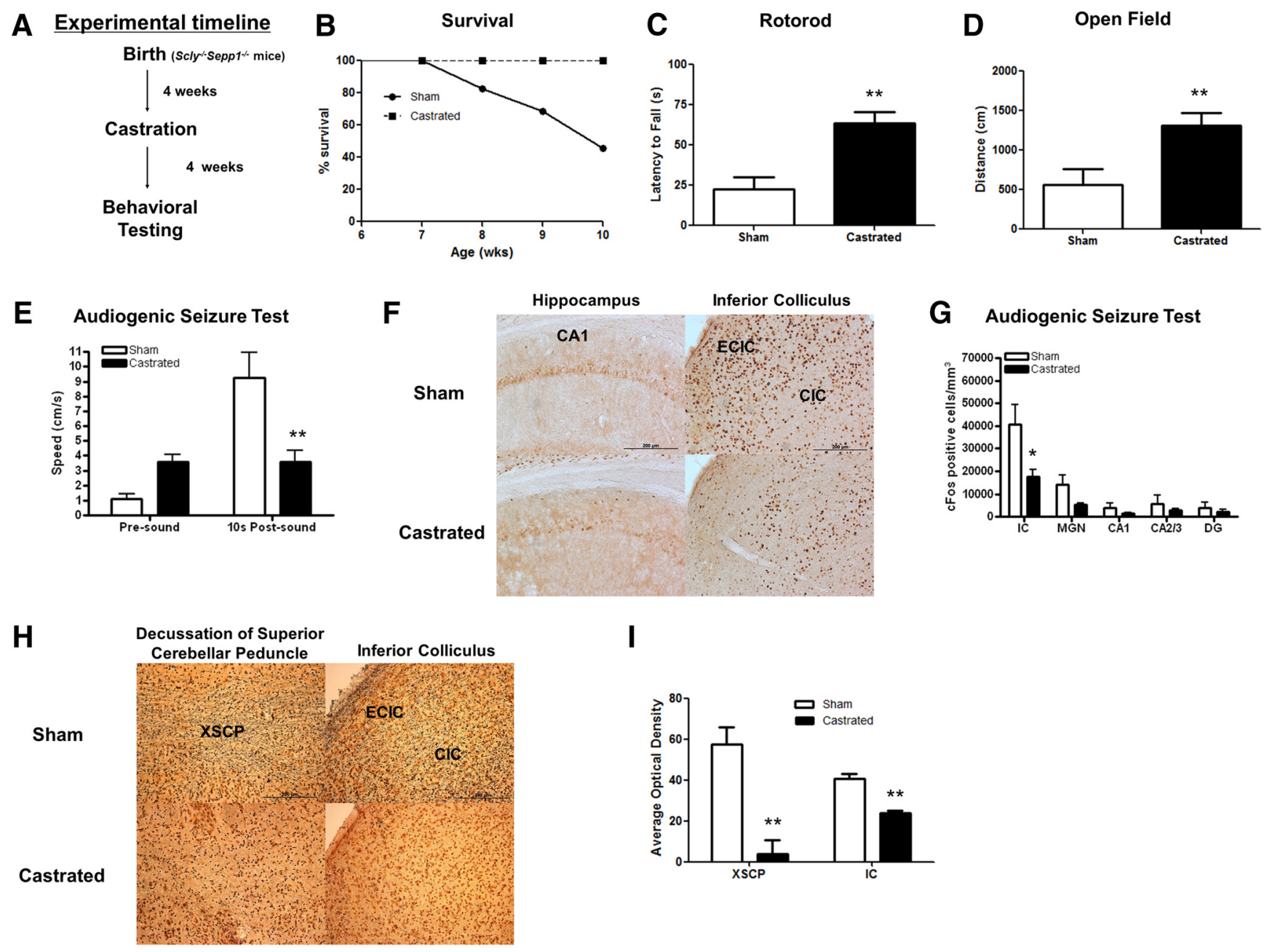

Figure 4. Castration of juvenile Scly ${ }^{-/-}$Sepp $1^{-/-}$mice promotes survival, prevents behavioral deficits, and attenuates neurodegeneration. $\boldsymbol{A}$, Experimental timeline. $\boldsymbol{B}$, Survival curve of sham $(n=31)$ and castrated $(n=20)$ Scly $^{-/-}$Sepp $1^{-/-}$mice. C, Mean ( \pm SEM) latency to fall off rotorod (sham: $n=7 ;$ castrated: $\left.n=17\right)$. D, Mean ( \pm SEM) distance traveled during the open field test (sham: $n=9$; castrated: $n=13$ ). $\boldsymbol{E}$, Mean ( \pm SEM) speed before $85 \mathrm{~dB}$ white noise and in the 10 s period after start of $85 \mathrm{~dB}$ white noise (sham: $n=5$; castrated: $n=16) . \boldsymbol{F}$, Images of cFos immunohistochemistry from sham and castrated Scly ${ }^{-1-}$ Sepp $1^{-1-}$ mice. $\boldsymbol{G}$, Mean ( \pm SEM) density of cFos-positive cells per $\mathrm{mm}^{3}$ ( $n=6$ per group). $\boldsymbol{H}$, Images of silver-stained brain sections from sham and castrated SCly ${ }^{-1-}$ Sepp $1^{-\prime-}$ mice containing the XSCP (left) and the IC (right). $I$, Mean ( \pm SEM) optical density of silver staining $(n=3$ per group). CIC, Central nucleus of inferior colliculus; DG, dentate gyrus; ECIC, external cortex of inferior colliculus; MGN, medial geniculate nucleus. ${ }^{*} p<0.05$. ${ }^{* *} p<0.01$. Scale bar, $200 \mu \mathrm{m}$.

to display symptoms of neurological dysfunction. At this time, mice were subjected to our modified open field procedure and thereafter killed for further analysis. Two-way ANOVA showed a significant sound $\times$ castration interaction effect $\left(F_{(1,18)}=5.836, p<0.05\right)$, and post hoc tests determined that sham Sepp $1^{-/-}$mice moved significantly faster in response to noise, as multiple mice exhibited wild running behavior $\left(t_{(18)}\right.$ $=2.990, p<0.05)$ (Fig. 7C). Histological analyses revealed that castration significantly diminished neurodegeneration in the IC $\left(t_{(7)}=2.415, p<0.05\right)$ and XSCP $\left(t_{(7)}=2.671, p<\right.$ 0.05 ) (Fig. $7 D, E$ ). Analysis of GPx activity on samples from Sepp $1^{-/-}$mice maintained on a Se-deficient diet for 5 weeks determined that castration resulted in a significant increase in brainstem GPx activity $\left(t_{(4)}=7.340, p<0.01\right.$ ) (Fig. $7 F$ ). Also, whereas the majority of animals were killed after 5 weeks on the Se-deficient diet, a small cohort of castrated animals $(n=$ 3 ) were kept on the Se-deficient diet until they exhibited overt neurological problems, which occurred 3 weeks later. In sum, these results demonstrate that castration delays the onset of neurological dysfunction in Sepp1 $1^{-1-}$ mice.
Castration of juvenile wild-type mice improves spatial learning, increases cortical GPx activity, and attenuates PV interneuron loss in response to periadolescent MK-801 exposure

In our final set of experiments, we raised male WT mice on a Se-deficient diet, castrated at 4 weeks of age (Fig. $8 A$ ), and further challenged mice with subanesthetic exposure ( 5 consecutive daily injections at $0.2 \mathrm{mg} / \mathrm{kg}$ ) to dizocilpine maleate (MK-801) at 6 weeks of age. MK-801 is a member of the family of noncompetitive NMDA receptor antagonists (also including ketamine and phencyclidine), which causes neurotoxicity in specific brain regions, most prominently the cingulate and retrosplenial cortices (Olney et al., 1989, 1991). Exposure to NMDA receptor antagonists activates NADPH oxidase, resulting in elevated ROS, and a subsequent reduction of Gad67 and PV expression (Behrens et al., 2007). We challenged mice at the onset of puberty because this represents a period when Se levels increase considerably in the testes (Behne et al., 1986) and the onset of susceptibility to MK801 neurotoxicity begins (Farber et al., 1995). Moreover, a recent study using a similar dosing procedure reported that exposure to 
A

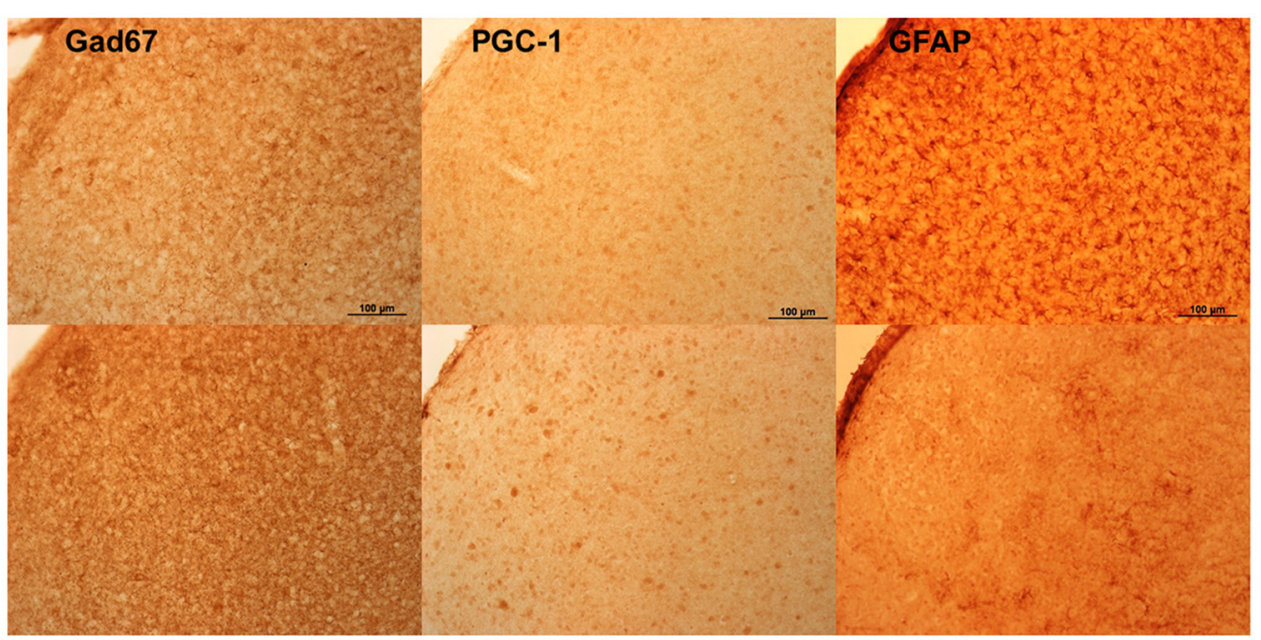

B

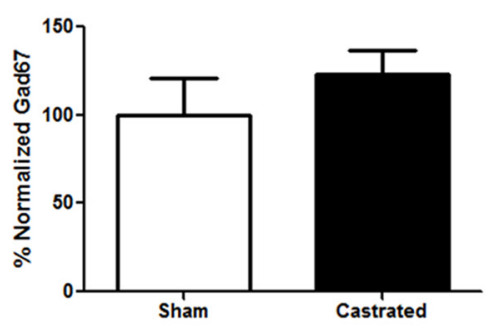

C

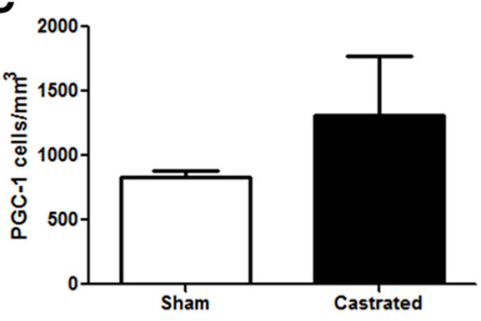

D

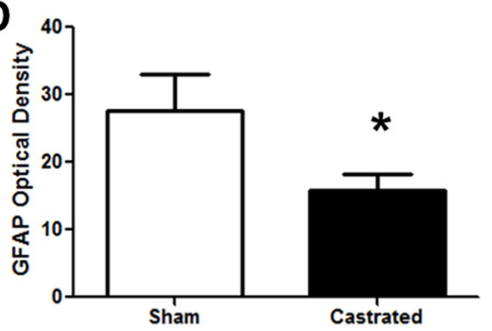

E

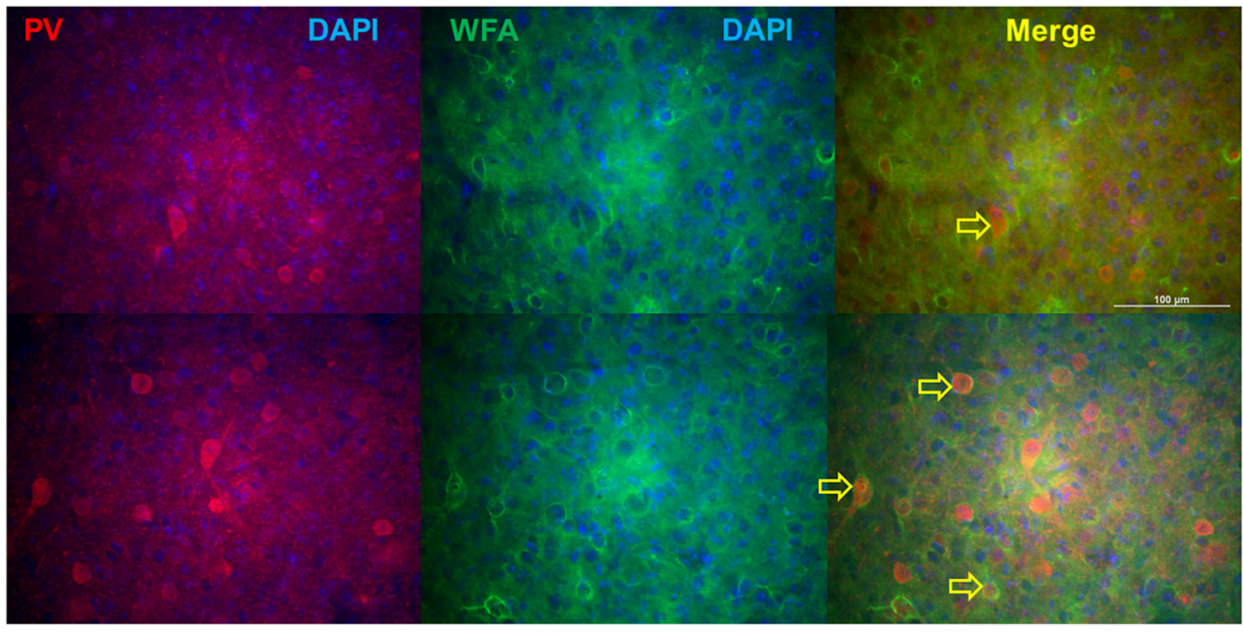

$\mathbf{F}$

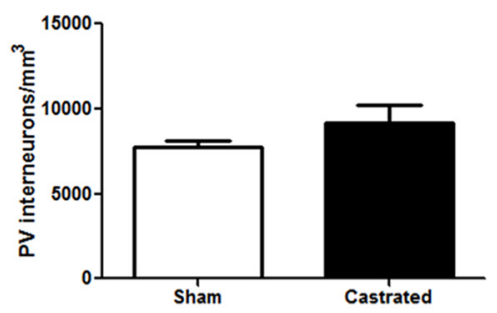

G

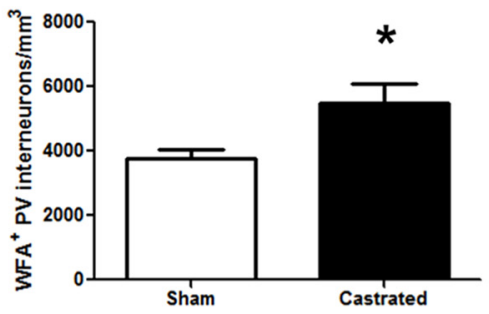

Figure 5. Castration attenuates oxidative stress and promotes maturation of GABAergic inhibition in the IC of SCly ${ }^{-1-} \mathrm{Sepp} 1^{-/-}$mice. $A$, Images of immunohistochemistry for Gad67, PGC-1, and GFAP in the IC of sham and castrated Scly ${ }^{-/}$Sepp $1^{-/-}$mice. B, Mean ( \pm SEM) normalized Gad67 optical density relative to sham Scly ${ }^{-/}$Sepp $1^{-/-}$mice $($sham: $n=4$; castrated: $n=5$ ). C, Mean ( \pm SEM) density of PGC-1 cells per $\mathrm{mm}^{3}$ (sham: $n=3$; castrated: $n=4$ ). D. Mean ( \pm SEM) GFAP optical density (sham: $n=5$; castrated: $\left.n=7\right)$. $\boldsymbol{E}$, Immunofluorescent images of PV (red) and WFA (green) from the IC of sham and castrated Scly ${ }^{-/}$Sepp $1^{-1-}$ mice. Yellow arrows indicate WFA-labeled PV interneurons in merged images. $\boldsymbol{F}$, Mean ( \pm SEM) density of PV interneurons per $\mathrm{mm}^{3}$. G, Mean ( \pm SEM) density of WFA-labeled PV interneurons per $\mathrm{mm}^{3}$ ( (sham: $n=4$; castrated: $n=5$ ). ${ }^{*} p<0.05$. Scale bar, $100 \mu \mathrm{m}$. 

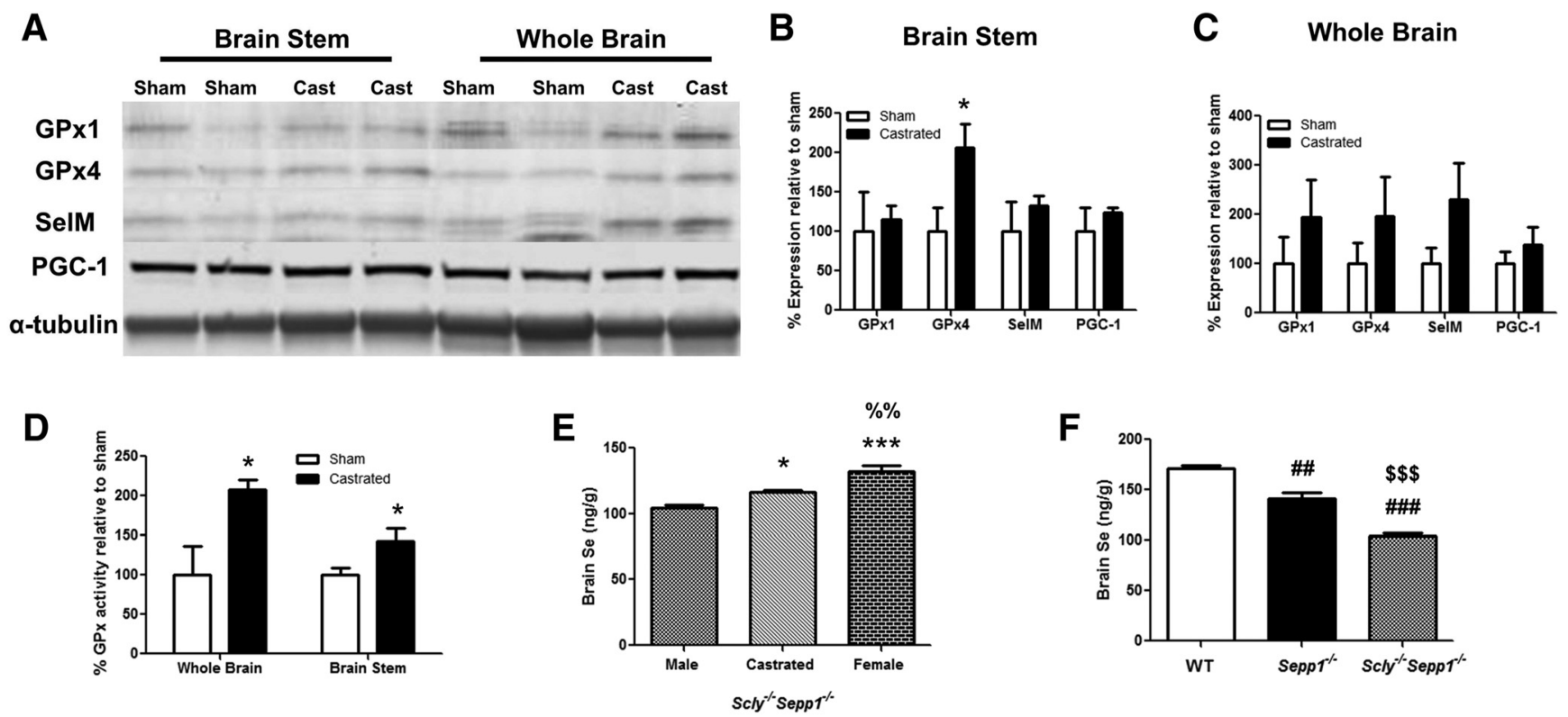

G

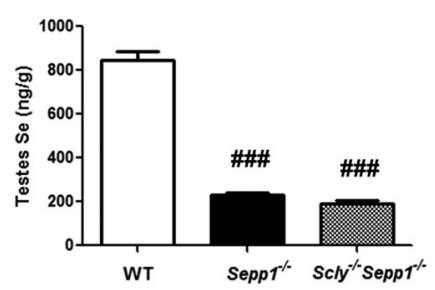

H

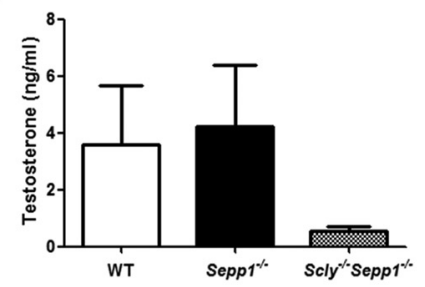

Figure 6. Castration increases brain selenoprotein and Se levels in Scly ${ }^{-/-}$Sepp $1^{-/-}$mice. $\boldsymbol{A}$, Western blot showing levels of GPx1, GPx4, SelM, PGC-1, and $\alpha$-tubulin in brainstem and whole-brain samples of sham and castrated Scly ${ }^{-/}$Sepp $1^{-/-}$mice. $\boldsymbol{B}$, Mean ( \pm SEM) normalized protein levels in brainstem relative to sham Scly ${ }^{-/}$Sepp ${ }^{-/-}$samples $(n=4$ per group). $\boldsymbol{C}$, Mean ( \pm SEM) normalized protein levels in whole brain ( $n=4$ per group). $\boldsymbol{D}$, Mean ( \pm SEM) normalized GPx activity in brainstem ( $n=8$ per group) and whole brain $(n=4$ or 5 per group) samples relative to sham Scly ${ }^{-1-}$ Sepp $1^{-1-}$ samples. $\boldsymbol{E}$, Mean ( \pm SEM) whole brain Se levels in male $(n=4)$, castrated $(n=5)$, and female $(n=4) S c l y{ }^{-1-}$ Sepp $1^{-1-}$ mice. $\boldsymbol{F}$, Mean $( \pm S E M)$ whole brain Se levels in male WT $(n=4)$, Sepp $1^{-/-}(n=6)$, and Scly ${ }^{-1-}$ Sepp $1^{-/-}(n=4)$ mice. G, Mean $\left( \pm\right.$ SEM) testes Se levels in male WT $(n=4)$, Sepp $1^{-/-}(n=6)$, and Scly ${ }^{-1-}$ Sepp $1^{-/-}(n=$ 4) mice. $\boldsymbol{H}$, Mean ( \pm SEM) testosterone levels in male WT $(n=5)$, Sepp $1^{-/-}(n=5)$, and Scly ${ }^{-1-}$ Sepp $1^{-/-}(n=4)$ mice. ${ }^{*} p<0.05$ compared with male Scly ${ }^{-/-}$Sepp $1^{-/-}$. ${ }^{* * *} p<0.001$ compared with male Scly ${ }^{-/-}$Sepp $1^{-/-} .{ }^{\%} \% p<0.01$ compared with castrated Scly ${ }^{-/-}$Sepp $1^{-/-} .{ }^{\# \#} p<0.01$ compared with male WT. ${ }^{\# \#} p<0.001$ compared with male WT. ${ }^{\$ \$} p<0.01$ compared with male Sepp $1^{-/-}$.

MK-801 impairs the maturation of cortical GABAergic inhibition (Thomases et al., 2013). Three weeks after the end of MK801 treatment, mice were evaluated for long-term consequences of periadolescent exposure. In addition to groups of noncastrated and castrated MK-801-treated mice, a control group was included that was neither castrated nor exposed to MK-801. On the rotorod, castrated MK-801-treated mice showed a nonsignificant tendency toward better performance relative to the other two groups $(p=0.1730)$ (Fig. $8 B)$. When tested on the Barnes maze, we observed a significant main effect of time on spatial learning, as indicated by a faster latency $\left(F_{(4,108)}=71.87, p<0.0001\right)$ and less errors $\left(F_{(4,108)}=71.87, p<0.0001\right)$ when locating the target hole (Fig. $8 C, D$ ). The castrated MK-801 group exhibited trends toward improved spatial learning that approached significance, as measured in terms of latency $(p=0.1157)$ and number of errors $(p=0.1132)$. Upon restriction of statistical analysis to the third block of trials, we found a significant main effect of group on the number of primary errors $\left(F_{(2,27)}=3.930, p<0.05\right)$, with post hoc tests showing that castrated MK-801-treated mice outperformed intact male MK-801-treated mice $(p<0.05)$ (Fig. $8 F)$. A similar nonsignificant trend was also observed for primary latency during this trial block $(p=0.1123)$ (Fig. $8 E)$. Mice were also tested for acoustic startle reactivity and prepulse inhibition, but all groups performed comparably (data not shown). Regional analysis of GPx activity showed that cortical levels significantly differed between groups $\left(F_{(2,11)}=6.440, p<0.05\right)$, as cortical GPx activity was elevated in castrated MK-801-treated mice relative to intact males receiving MK-801 treatment $(p<0.05)$ (Fig. $8 G)$. We also investigated the effect of MK-801 treatment upon PV interneuron maturation. Our analyses focused on the retrosplenial cortex, as this region is implicated in spatial learning (Czajkowski et al., 2014) and adversely affected by MK-801 treatment (Olney et al., 1989; Olney et al., 1991). In this region, we observed significant differences in PV interneuron density between groups $\left(F_{(2,15)}=4.817, p<0.05\right)$ (Fig. $\left.8 H, I\right)$. MK-801treated mice displayed a reduced density of PV interneurons relative to control mice ( $p<0.05)$, and this reduction was partially attenuated by castration. In addition, mice treated with MK-801 also showed trends toward a reduced density of PNNlabeled PV interneurons relative to the other groups $(p=0.1267)$ (Fig. $8 H, J$ ).

\section{Discussion}

This study details the remarkable neuroprotective benefit of castration in Se-compromised mice, due to competition between brain and testes for Se utilization. Our results demonstrate that 
A

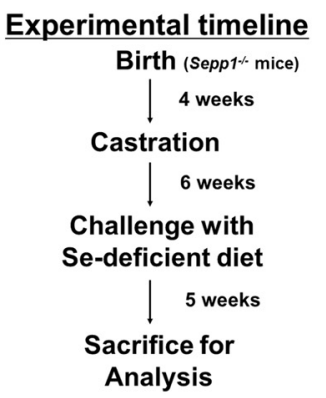

D

Sham

Castrated
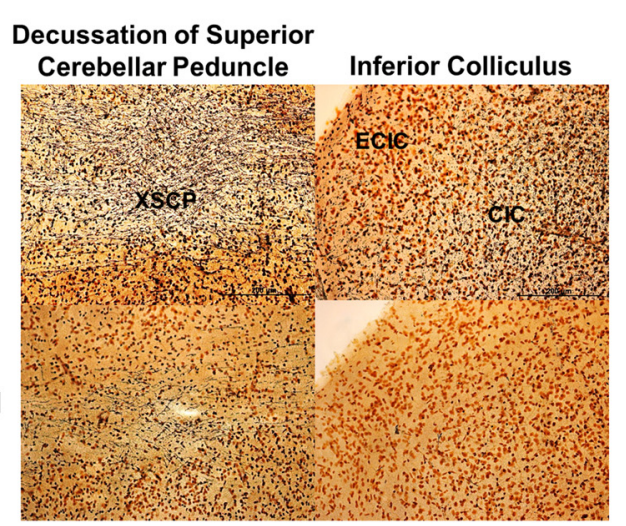

B

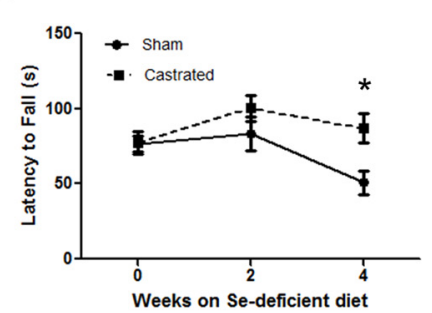

E

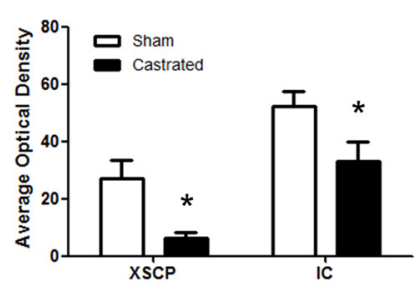

C Audiogenic Seizure Test

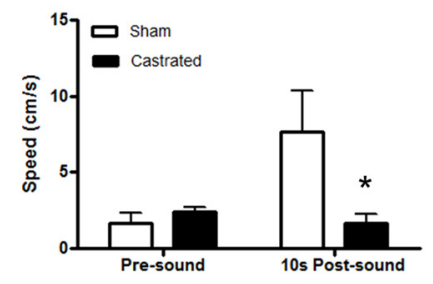

$\mathbf{F}$

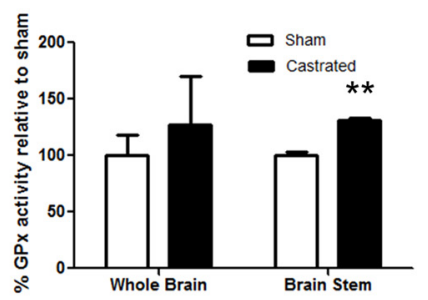

Figure 7. Castration delays neurological impairment and neurodegeneration in Sepp $1^{-/-}$mice challenged with a Se-deficient diet. $A$, Experimental timeline. $B$, Mean $( \pm S E M)$ latency to fall off rotorod ( $n=10$ per group). C, Mean ( \pm SEM) speed before $85 \mathrm{~dB}$ white noise and in the 10 s period immediately after start of $85 \mathrm{~dB}$ white noise $(n=10$ per group). $\boldsymbol{D}$, Images of silver-stained brain sections containing the XSCP (left) and the IC (right). $\boldsymbol{E}$, Mean ( \pm SEM) optical density of silver staining in sham $(n=5)$ and castrated $(n=4)$ Sepp $1^{-/-}$mice. $\boldsymbol{F}$, Mean $( \pm$ SEM) normalized GPX activity in brainstem and whole-brain samples ( $n=6$ per group). CIC, Central nucleus of inferior colliculus; ECIC, external cortex of inferior colliculus. ${ }^{*} p<0.05 .{ }^{* *} p<0.01$. Scale bar, 200 $\mu \mathrm{m}$.

castration prevents neurodegeneration, promotes normal excitatory/inhibitory balance, and improves behavioral performance in two transgenic mouse strains with impaired Se metabolism. Furthermore, in WT mice challenged with both a Se-deficient diet and periadolescent MK-801 exposure, castration improved spatial learning and attenuated MK-801-induced PV interneuron loss. Finally, castration resulted in elevated brain GPx activity, supporting our hypothesis that the brain and testes compete under conditions of Se deficiency.

Prior studies on rodents administered Se-deficient diets have reported deficits in spermatogenesis (Watanabe and Endo, 1991), impaired hippocampal synaptic plasticity (Peters et al., 2006), and increased susceptibility to neurotoxicity (Savaskan et al., 2003). When dietary Se intake is insufficient, Se levels are preferentially retained in the brain and testes, although they decline in other tissues, such as liver, kidney, and muscle (for review, see Burk and Hill, 2009). ApoER2 and Sepp1 are required for the privileged retention of Se, as ApoER2 $2^{-1-}$ and Sepp $1^{-/-}$ mice have decreased Se levels in brain and testes (Hill et al., 2003; Burk et al., 2007), and both strains develop neurological dysfunction upon administration of a Se-deficient diet (Valentine et al., 2008). Of particular relevance to our results, earlier studies on Se-deficient rats receiving a radioactive dose of ${ }^{75} \mathrm{Se}$ revealed that, upon death, the testes contained the highest percentage of ${ }^{75} \mathrm{Se}$ among organs (Burk et al., 1972; Brown and Burk, 1973). In our time course study of Se-supplemented male Scly ${ }^{-1} \operatorname{Sepp} 1^{-/-}$ mice, overt neurological problems did not become apparent until puberty, and these deficits were largely prevented by prepubescent castration. Testes Se content increases several-fold during puberty (Behne et al., 1986), and our results show that, under Se-compromised conditions, the growing demand of the testes sequesters Se away from the brain. The fact that castration ex- erted a neuroprotective effect in $S e p p 1^{-/-}$and $S c l y^{-/-} S e p p 1^{-/-}$ mice was surprising, particularly because testes Se content was reduced approximately fourfold in these mice compared with WT controls. The finding that Sepp 1 deletion had a greater effect on Se levels in testes than in brain suggests that Sepp1 plays a more important role in testes function. This notion is supported by earlier reports that providing Se supplementation to Sepp $1^{-/-}$ mice mitigates neurological impairments (Hill et al., 2004) but does not improve fertility (Olson et al., 2005).

For our experiments involving mice lacking Sepp1, we observed neurodegeneration in circumscribed regions related to motor and auditory function. With respect to motor control, damage was consistently seen along the superior cerebellar peduncles, a fiber tract that originates in the cerebellar nuclei, decussates in the caudal midbrain, and terminates in the contralateral red nucleus. Degeneration was also readily apparent in the IC, a vital processing site for auditory information that has been reported to be the most metabolically active brain region in rats (Sokoloff et al., 1977) and monkeys (Kennedy et al., 1978). Behaviorally, this region is implicated in multiple processes, including sound localization (Wenstrup et al., 1986), modulation of prepulse inhibition (Li et al., 1998; for review, see Fendt et al., 2001), and auditory fear conditioning (LeDoux et al., 1984). Moreover, diminished GABAergic inhibition in the IC is associated with audiogenic seizures in several rodent studies (for review, see Faingold, 2002). Consistent with this viewpoint, we found that mice exhibiting audiogenic seizures had reduced expression of Gad67 and PV in the IC, and also displayed increased GFAP immunoreactivity, indicative of elevated oxidative stress.

Our findings also provide support for the notion that redox imbalance impedes the development and function of PV interneurons. PV interneurons comprise a class of GABAergic cells 


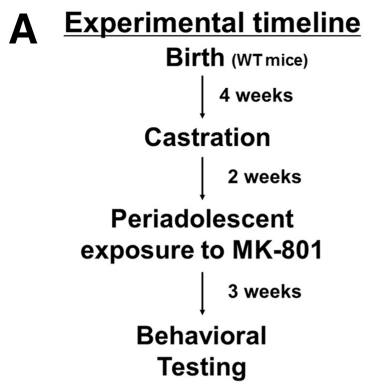

E

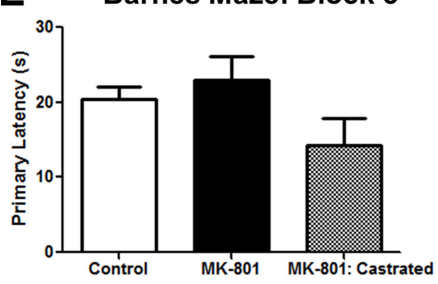

B

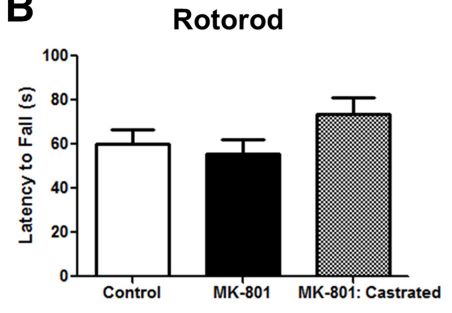

$\mathbf{F}$

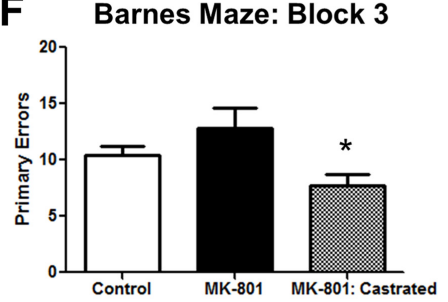

C
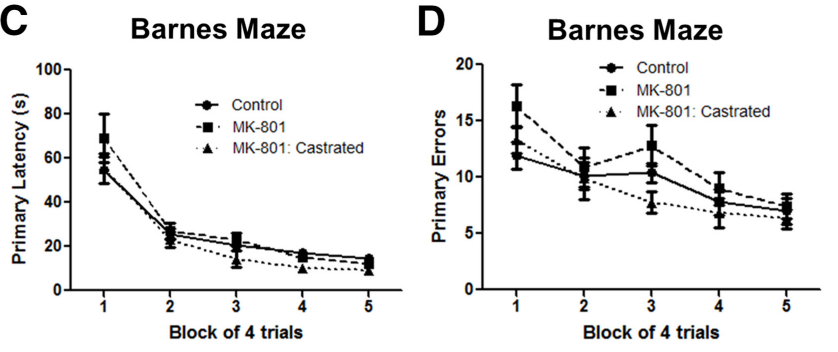

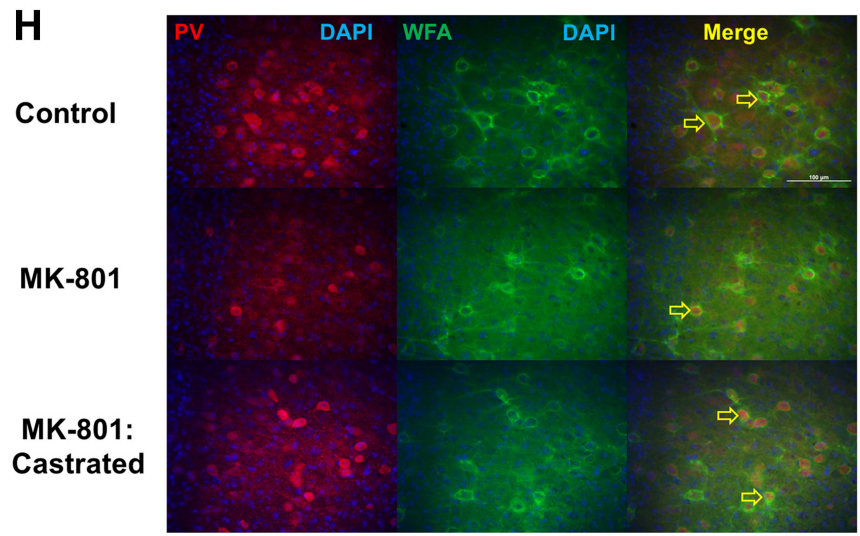

G

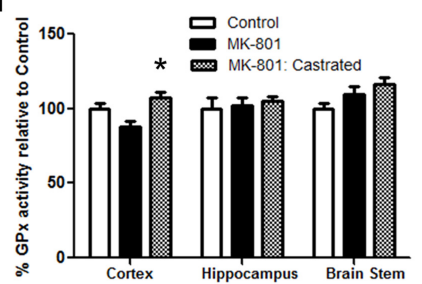

I

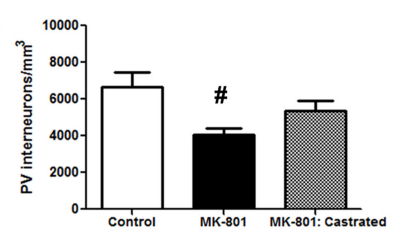

J

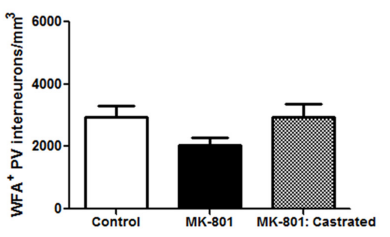

Figure 8. Castration provides neuroprotection to wild-type mice challenged with periadolescent MK-801 exposure and a Se-deficient diet. $\boldsymbol{A}$, Experimental timeline. $\boldsymbol{B}$, Mean ( \pm SEM) latency to fall off rotorod. C, Mean ( \pm SEM) latency to locate the escape tunnel during Barnes maze training. $D$, Mean ( \pm SEM) number of incorrect holes checked before locating the escape tunnel during training. $E$, Mean ( \pm SEM) latency to locate the escape tunnel during trial block 3.F, Mean $( \pm$ SEM) number of incorrect holes checked before locating the escape tunnel during trial block 3 ( $n=10$ per group). G, Mean ( \pm SEM) normalized GPx activity in samples from cortex, hippocampus, and brainstem ( $n=4$ per group). $\boldsymbol{H}$, Immunofluorescent images of PV (red) and WFA (green) from the retrosplenial cortex. Yellow arrows indicate WFA-labeled PV interneurons in merged images. $I$, Mean ( \pm SEM) density of PV interneurons per mm ${ }^{3}$. J, Mean ( \pm SEM) density of WFA-labeled PV interneurons per mm ${ }^{3} .{ }^{*} p<0.05$ compared with MK-801 group. ${ }^{\#} p<0.05$ compared with Control group. Scale bar, $100 \mu \mathrm{m}$.

with fast-spiking properties that synchronize activity within populations of principal neurons (for review, see $\mathrm{Hu}$ et al., 2014). Because of their intrinsic properties, these interneurons have high metabolic demands and are particularly susceptible to oxidative stress (Behrens et al., 2007). Recent evidence also demonstrates that PV itself acts as a metal-dependent antioxidant and that PV levels decline in response to redox imbalance (Permyakov et al., 2014). In addition, neuronal ablation of selenoprotein synthesis in mice results in impaired PV interneuron development and death by P14 (Wirth et al., 2010). We previously showed that ApoER2 is expressed by PV interneurons (Pitts et al., 2012) and in this study find enriched expression of PGC-1 and selenophosphate synthetase 2 in ApoER2-expressing PV interneurons (Fig. 2). This indicates that Sepp1 is targeted to metabolically active PV interneurons, which represent primary sites of selenoprotein synthesis. Moreover, ApoER2-expressing PV interneurons are especially abundant in brain regions exhibiting neurodegeneration in $S e p p 1^{-/-}$and $S c l y^{-1-} S e p p 1^{-/-}$mice, lending evidence for the importance of selenoproteins in maintaining the integrity of PV interneurons.
Whereas PV expression begins during the second postnatal week in rodents (del Río et al., 1994), the development of PNNs that preferentially encapsulate PV interneurons begins later and continues into adolescence. Maturation of PNNs coincides with the closure of critical periods of neurodevelopment, during which sensory experience molds neuronal circuitry that is largely maintained throughout adulthood (for review, see Hensch, 2005). PNNs limit plasticity and maintain excitatory/inhibitory balance (Beurdeley et al., 2012) but also serve as protective barriers against oxidative stress (Suttkus et al., 2012; Cabungcal et al., 2013). Interestingly, in male $S c l y^{-1-} S e p p 1^{-1-}$ mice, the density of PV interneurons and PNN-labeled PV interneurons in the IC appeared normal at 4 weeks, but not at 8 weeks of age. This reveals impaired maturation, but not initial development, of PV interneurons. Moreover, castration was found to promote PV interneuron maturation and prevent audiogenic seizures.

A reduction of markers (PV, Gad67) related to cortical inhibition is one of the most salient findings in schizophrenia and is thought to underlie the observed cognitive deficits (for review, see Lewis et al., 2012). PV interneurons modulate the strength of gamma oscillations (Sohal et al., 2009), which contribute to 
working memory and cognition. Studies in rodents have shown that redox imbalance during development results in reduced PV expression, diminished power of gamma oscillations, and schizophrenia-related behavior deficits in adulthood (Steullet et al., 2010; Cabungcal et al., 2013; Jiang et al., 2013). A recent study reported that neonatal ventral hippocampus lesions (NVHL), a developmental model of schizophrenia, increased oxidative stress during development and caused a reduction of cortical PV interneurons in adulthood, as well as behavioral and electrophysiological deficits related to schizophrenia (Cabungcal et al., 2014). Moreover, juvenile antioxidant treatment attenuated the NVHL-induced increase in oxidative stress and prevented all the aforementioned deficits from occurring in adulthood. Also, an earlier study found that NVHL rats exhibited acoustic hypersensitivity and altered electrophysiological responses within the IC (Macedo et al., 2010), potentially due to redox imbalance caused by the NVHL. With specific respect to Se, a microarray analysis of postmortem cortical tissue identified Sepp 1 as being significantly downregulated in patients with schizophrenia (Hakak et al., 2001). Also, of potential importance, early-onset schizophrenia is biased toward men (for review, see Häfner et al., 1998), and one possible explanation for the increased susceptibility of males during puberty is that the antioxidant resources of the brain are compromised by the growing requirement of the testes for Se.

In conclusion, this study reports the striking neuroprotective effect provided by castration under Se-compromised conditions, which offers novel insight into sex-specific differences in Se metabolism. We find that, when selenoprotein levels fall below a critical threshold, PV interneurons become dysfunctional, with the outcome being hyperexcitability, seizures, and neurodegeneration. Moreover, our results show that castration provides neuroprotection by boosting selenoprotein levels above this critical threshold. In addition, brain selenoprotein expression appears to be of particular importance during puberty, a period when inhibitory networks become stabilized and the demand of the testes for Se increases. These findings may have significant implications for the prevention of neurodevelopmental disorders characterized by aberrant excitatory/inhibitory balance, such as schizophrenia and epilepsy.

\section{References}

Andersen OM, Yeung CH, Vorum H, Wellner M, Andreassen TK, Erdmann B, Mueller EC, Herz J, Otto A, Cooper TG, Willnow TE (2003) Essential role of the apolipoprotein E receptor-2 in sperm development. J Biol Chem 278:23989-23995. CrossRef Medline

Behne D, Duk M, Elger W (1986) Selenium content and glutathione peroxidase activity in the testis of the maturing rat. J Nutr 116:1442-1447. Medline

Behrens MM, Ali SS, Dao DN, Lucero J, Shekhtman G, Quick KL, Dugan LL (2007) Ketamine-induced loss of phenotype of fast-spiking interneurons is mediated by NADPH-oxidase. Science 318:1645-1647. CrossRef Medline

Beurdeley M, Spatazza J, Lee HH, Sugiyama S, Bernard C, Di Nardo AA, Hensch TK, Prochiantz A (2012) Otx2 binding to perineuronal nets persistently regulates plasticity in the mature visual cortex. J Neurosci 32:9429-9437. CrossRef Medline

Brown DG, Burk RF (1973) Selenium retention in tissues and sperm of rats fed a Torula yeast diet. J Nutr 103:102-108. Medline

Burk RF, Hill KE (2009) Selenoprotein P-expression, functions, and roles in mammals. Biochim Biophys Acta 1790:1441-1447. CrossRef Medline

Burk RF, Brown DG, Seely RJ, Scaief CC 3rd (1972) Influence of dietary and injected selenium on whole-body retention, route of excretion, and tissue retention of 75SeO3 2 in the rat. J Nutr 102:1049-1055. Medline

Burk RF, Hill KE, Olson GE, Weeber EJ, Motley AK, Winfrey VP, Austin LM (2007) Deletion of apolipoprotein E receptor-2 in mice lowers brain selenium and causes severe neurological dysfunction and death when a low-selenium diet is fed. J Neurosci 27:6207-6211. CrossRef Medline
Byrns CN, Pitts MW, Gilman CA, Hashimoto AC, Berry MJ (2014) Mice lacking selenoprotein $\mathrm{P}$ and selenocysteine lyase exhibit severe neurological dysfunction, neurodegeneration, and audiogenic seizures. J Biol Chem 289:9662-9674. CrossRef Medline

Cabungcal JH, Steullet P, Morishita H, Kraftsik R, Cuenod M, Hensch TK, Do KQ (2013) Perineuronal nets protect fast-spiking interneurons against oxidative stress. Proc Natl Acad Sci U S A 110:9130-9135. CrossRef Medline

Cabungcal JH, Counotte DS, Lewis EM, Tejeda HA, Piantadosi P, Pollock C, Calhoon GG, Sullivan EM, Presgraves E, Kil J, Hong LE, Cuenod M, Do KQ, O’Donnell P (2014) Juvenile antioxidant treatment prevents adult deficits in a developmental model of schizophrenia. Neuron 83:10731084. CrossRef Medline

Cowell RM, Blake KR, Russell JW (2007) Localization of the transcriptional coactivator PGC-1alpha to GABAergic neurons during maturation of the rat brain. J Comp Neurol 502:1-18. CrossRef Medline

Czajkowski R, Jayaprakash B, Wiltgen B, Rogerson T, Guzman-Karlsson MC, Barth AL, Trachtenberg JT, Silva AJ (2014) Encoding and storage of spatial information in the retrosplenial cortex. Proc Natl Acad Sci U S A 111:8661-8666. CrossRef Medline

del Río JA, de Lecea L, Ferrer I, Soriano E (1994) The development of parvalbumin-immunoreactivity in the neocortex of the mouse. Brain Res Dev Brain Res 81:247-259. CrossRef Medline

Esaki N, Nakamura T, Tanaka H, Soda K (1982) Selenocysteine lyase, a novel enzyme that specifically acts on selenocysteine: mammalian distribution and purification and properties of pig liver enzyme. J Biol Chem 257:4386-4391. Medline

Faingold CL (2002) Role of GABA abnormalities in the inferior colliculus pathophysiology-audiogenic seizures. Hear Res 168:223-237. CrossRef Medline

Farber NB, Wozniak DF, Price MT, Labruyere J, Huss J, St. Peter H, Olney JW (1995) Age-specific neurotoxicity in the rat associated with NMDA receptor blockade: potential relevance to schizophrenia? Biol Psychiatry 38:788-796. CrossRef Medline

Fendt M, Li L, Yeomans JS (2001) Brain stem circuits mediating prepulse inhibition of the startle reflex. Psychopharmacology 156:216-224. CrossRef Medline

Häfner H, an der Heiden W, Behrens S, Gattaz WF, Hambrecht M, Loffler W, Löffler W, Maurer K, Munk-Jørgensen P, Nowotny B, Riecher-Rössler A, Stein A (1998) Causes and consequences of the gender difference in age at onset of schizophrenia. Schizophr Bull 24:99-113. CrossRef Medline

Hakak Y, Walker JR, Li C, Wong WH, Davis KL, Buxbaum JD, Haroutunian V, Fienberg AA (2001) Genome-wide expression analysis reveals dysregulation of myelination-related genes in chronic schizophrenia. Proc Natl Acad Sci U S A 98:4746-4751. CrossRef Medline

Härtig W, Brauer K, Brückner G (1992) Wisteria floribunda agglutininlabelled nets surround parvalbumin-containing neurons. Neuroreport 3:869-872. CrossRef Medline

Hensch TK (2005) Critical period plasticity in local cortical circuits. Nat Rev Neurosci 6:877-888. CrossRef Medline

Hill KE, Zhou J, McMahan WJ, Motley AK, Atkins JF, Gesteland RF, Burk RF (2003) Deletion of selenoprotein P alters distribution of selenium in the mouse. J Biol Chem 278:13640-13646. CrossRef Medline

Hill KE, Zhou J, McMahan WJ, Motley AK, Burk RF (2004) Neurological dysfunction occurs in mice with targeted deletion of the selenoprotein $\mathrm{P}$ gene. J Nutr 134:157-161. Medline

Hu H, Gan J, Jonas P (2014) Interneurons: fast-spiking, parvalbumin(+) GABAergic interneurons: from cellular design to microcircuit function. Science 345:1255263. CrossRef Medline

Jiang Z, Rompala GR, Zhang S, Cowell RM, Nakazawa K (2013) Social isolation exacerbates schizophrenia-like phenotypes via oxidative stress in cortical interneurons. Biol Psychiatry 73:1024-1034. CrossRef Medline

Kennedy C, Sakurada O, Shinohara M, Jehle J, Sokoloff L (1978) Local cerebral glucose utilization in the normal conscious macaque monkey. Ann Neurol 4:293-301. CrossRef Medline

Koh TS, Benson TH (1983) Critical re-appraisal of fluorometric method for determination of selenium in biological materials. J Assoc Off Anal Chem 66:918-926. Medline

LeDoux JE, Sakaguchi A, Reis DJ (1984) Subcortical efferent projections of the medial geniculate nucleus mediate emotional responses conditioned to acoustic stimuli. J Neurosci 4:683-698. Medline

Lewis DA, Curley AA, Glausier JR, Volk DW (2012) Cortical parvalbumin 
interneurons and cognitive dysfunction in schizophrenia. Trends Neurosci 35:57-67. CrossRef Medline

Li L, Korngut LM, Frost BJ, Beninger RJ (1998) Prepulse inhibition following lesions of the inferior colliculus: prepulse intensity functions. Physiol Behav 65:133-139. CrossRef Medline

Lucas EK, Dougherty SE, McMeekin LJ, Reid CS, Dobrunz LE, West AB, Hablitz JJ, Cowell RM (2014) PGC-1alpha provides a transcriptional framework for synchronous neurotransmitter release from parvalbuminpositive interneurons. J Neurosci 34:14375-14387. CrossRef Medline

Macedo CE, Angst MJ, Guiberteau T, Brasse D, O'Brien TJ, Sandner G (2010) Acoustic hypersensitivity in adult rats after neonatal ventral hippocampus lesions. Behav Brain Res 207:161-168. CrossRef Medline

Olney JW, Labruyere J, Price MT (1989) Pathological changes induced in cerebrocortical neurons by phencyclidine and related drugs. Science 244: 1360-1362. CrossRef Medline

Olney JW, Labruyere J, Wang G, Wozniak DF, Price MT, Sesma MA (1991) NMDA antagonist neurotoxicity: mechanism and prevention. Science 254:1515-1518. CrossRef Medline

Olson GE, Winfrey VP, Nagdas SK, Hill KE, Burk RF (2005) Selenoprotein $\mathrm{P}$ is required for mouse sperm development. Biol Reprod 73:201-211. CrossRef Medline

Olson GE, Winfrey VP, Nagdas SK, Hill KE, Burk RF (2007) Apolipoprotein E receptor-2 (ApoER2) mediates selenium uptake from selenoprotein $\mathrm{P}$ by the mouse testis. J Biol Chem 282:12290-12297. CrossRef Medline

Paxinos G, Franklin K (2004) The mouse brain in stereotaxic coordinates, 2nd edition. New York: Elsevier Academic.

Permyakov SE, Kazakov AS, Avkhacheva NV, Permyakov EA (2014) Parvalbumin as a metal-dependent antioxidant. Cell Calcium 55:261-268. CrossRef Medline

Peters MM, Hill KE, Burk RF, Weeber EJ (2006) Altered hippocampus synaptic function in selenoprotein P deficient mice. Mol Neurodegener 1:12. CrossRef Medline

Pitts MW, Raman AV, Hashimoto AC, Todorovic C, Nichols RA, Berry MJ (2012) Deletion of selenoprotein P results in impaired function of parvalbumin interneurons and alterations in fear learning and sensorimotor gating. Neuroscience 208:58-68. CrossRef Medline

Pitts MW, Reeves MA, Hashimoto AC, Ogawa A, Kremer P, Seale LA, Berry MJ (2013) Deletion of selenoprotein M leads to obesity without cognitive deficits. J Biol Chem 288:26121-26134. CrossRef Medline

Raman AV, Pitts MW, Seyedali A, Hashimoto AC, Seale LA, Bellinger FP, Berry MJ (2012) Absence of selenoprotein P but not selenocysteine lyase results in severe neurological dysfunction. Genes Brain Behav 11:601613. CrossRef Medline

Savaskan NE, Bräuer AU, Kühbacher M, Eyüpoglu IY, Kyriakopoulos A, Ninnemann O, Behne D, Nitsch R (2003) Selenium deficiency increases susceptibility to glutamate-induced excitotoxicity. FASEB J 17:112-114. CrossRef Medline
Schomburg L, Schweizer U (2009) Hierarchical regulation of selenoprotein expression and sex-specific effects of selenium. Biochim Biophys Acta 1790:1453-1462. CrossRef Medline

Seale LA, Hashimoto AC, Kurokawa S, Gilman CL, Seyedali A, Bellinger FP, Raman AV, Berry MJ (2012) Disruption of the selenocysteine lyasemediated selenium recycling pathway leads to metabolic syndrome in mice. Mol Cell Biol 32:4141-4154. CrossRef Medline

Sheehan TM, Gao M (1990) Simplified fluorometric assay of total selenium in plasma and urine. Clin Chem 36:2124-2126. Medline

Sohal VS, Zhang F, Yizhar O, Deisseroth K (2009) Parvalbumin neurons and gamma rhythms enhance cortical circuit performance. Nature 459: 698-702. CrossRef Medline

Sokoloff L, Reivich M, Kennedy C, Des Rosiers MH, Patlak CS, Pettigrew KD, Sakurada O, Shinohara M (1977) The $\left[{ }^{14} \mathrm{C}\right]$ deoxyglucose method for the measurement of local cerebral glucose utilization: theory, procedure, and normal values in the conscious and anesthetized albino rat. J Neurochem 28:897-916. CrossRef Medline

Steullet P, Cabungcal JH, Kulak A, Kraftsik R, Chen Y, Dalton TP, Cuenod M, Do KQ (2010) Redox dysregulation affects the ventral but not dorsal hippocampus: impairment of parvalbumin neurons, gamma oscillations, and related behaviors. J Neurosci 30:2547-2558. CrossRef Medline

St-Pierre J, Drori S, Uldry M, Silvaggi JM, Rhee J, Jäger S, Handschin C, Zheng K, Lin J, Yang W, Simon DK, Bachoo R, Spiegelman BM (2006) Suppression of reactive oxygen species and neurodegeneration by the PGC-1 transcriptional coactivators. Cell 127:397-408. CrossRef Medline

Suttkus A, Rohn S, Jäger C, Arendt T, Morawski M (2012) Neuroprotection against iron-induced cell death by perineuronal nets: an in vivo analysis of oxidative stress. Am J Neurodegener Dis 1:122-129. Medline

Thomases DR, Cass DK, Tseng KY (2013) Periadolescent exposure to the NMDA receptor antagonist MK-801 impairs the functional maturation of local GABAergic circuits in the adult prefrontal cortex. J Neurosci 33:26-34. CrossRef Medline

Valentine WM, Abel TW, Hill KE, Austin LM, Burk RF (2008) Neurodegeneration in mice resulting from loss of functional selenoprotein $\mathrm{P}$ or its receptor apolipoprotein E receptor 2. J Neuropathol Exp Neurol 67: 68-77. CrossRef Medline

Watanabe T, Endo A (1991) Effects of selenium deficiency on sperm morphology and spermatocyte chromosomes in mice. Mutat Res 262:93-99. CrossRef Medline

Wenstrup JJ, Ross LS, Pollak GD (1986) Binaural response organization within a frequency-band representation of the inferior colliculus: implications for sound localization. J Neurosci 6:962-973. Medline

Wirth EK, Conrad M, Winterer J, Wozny C, Carlson BA, Roth S, Schmitz D, Bornkamm GW, Coppola V, Tessarollo L, Schomburg L, Köhrle J, Hatfield DL, Schweizer U (2010) Neuronal selenoprotein expression is required for interneuron development and prevents seizures and neurodegeneration. FASEB J 24:844-852. CrossRef Medline 